\title{
Protective Effect of a Locked Retinal Chromophore Analog against Light-Induced Retinal Degeneration
}

\author{
Songqi Gao, Tanu Parmar, Grazyna Palczewska, Zhiqian Dong, Marcin Golczak, \\ Krzysztof Palczewski, and Beata Jastrzebska
}

Department of Pharmacology, School of Medicine (S.G., T.P., M.G., K.P., B.J.) and Cleveland Center for Membrane and Structural Biology (M.G., K.P., B.J.), Case Western Reserve University, and Polgenix Inc., Department of Medical Devices (G.P., Z.D.), Cleveland, Ohio

Received March 26, 2018; accepted July 11, 2018

\section{ABSTRACT}

Continuous regeneration of the 11-cis-retinal visual chromophore from all-trans-retinal is critical for vision. Insufficiency of 11-cis-retinal arising from the dysfunction of key proteins involved in its regeneration can impair retinal health, ultimately leading to loss of human sight. Delayed recovery of visual sensitivity and night blindness caused by inadequate regeneration of the visual pigment rhodopsin are typical early signs of this condition. Excessive concentrations of unliganded, constitutively active opsin and increased levels of all-trans-retinal and its byproducts in photoreceptors also accelerate retinal degeneration after light exposure. Exogenous 9-cis-retinal isochromophore can reduce the toxicity of ligand-free opsin but fails to prevent the buildup of retinoid photoproducts when their clearance is defective in human retinopathies, such as Stargardt disease or age-related macular degeneration. Here we evaluated the effect of a locked chromophore analog, 11-cis-6-membered ring-retinal against bright light-induced retinal degeneration in Abca4 ${ }^{-1-} \mathrm{Rdh}^{-1-}$ mice. Using in vivo imaging techniques, optical coherence tomography, scanning laser ophthalmoscopy, and two-photon microscopy, along with in vitro histologic analysis of retinal morphology, we found that treatment with 11-cis-6-membered ring-retinal before light stimulation prevented rod and cone photoreceptor degradation and preserved functional acuity in these mice. Moreover, additive accumulation of 11-cis-6-membered ring-retinal measured in the eyes of these mice by quantitative liquid chromatography-mass spectrometry indicated stable binding of this retinoid to opsin. Together, these results suggest that eliminating excess of unliganded opsin can prevent light-induced retinal degeneration in $\mathrm{Abca}^{-/-} \mathrm{Rdh8^{-/- }}$ mice.

\section{Introduction}

Visual perception starts when a photon stimulates an isomerization of the 11-cis-retinal chromophore of rhodopsin in the retina to its all-trans configuration. This change leads to conformational rearrangements of the protein's helical bundles, allowing binding of the heterotrimeric G-protein transducin and initiation of signal transduction (Park et al., 2008; Jastrzebska, 2013). Eventually, the transiently formed complex between rhodopsin and G protein dissociates and alltrans-retinal leaves the binding pocket, resulting in formation of free opsin and free all-trans-retinal. To sustain vertebrate vision and preserve retinal health, continuous regeneration of visual pigment is essential (Rando, 1996; Palczewski, 2006). The supply of 11-cis-retinal results either from the dietary ingredients like $\beta$-carotene or through the regeneration of

This research was supported by grants from the National Institutes of Health (NIH) [EY025214, EY027283, EY024864, EY009339, EY025451, EY023948, and P30EY011373]

https://doi.org/10.1124/mol.118.112581. released all-trans-retinal back to its 11-cis form (Maeda et al., 2011b; Kiser et al., 2012, 2014; von Lintig, 2012). The latter is achieved by the so-called visual (retinoid) cycle. The proper function of proteins involved in retinoid renewal is critical for continuous regeneration of 11-cis-retinal needed to form rhodopsin and other visual pigments. Excessive light-induced release of all-trans-retinal from the visual pigment can be detrimental to photoreceptors (Maeda et al., 2008; Chen et al., 2012).

Thus, clearance of all-trans-retinal and its toxic byproducts generated by photoreceptor cells is vital for retinal health (Travis et al., 2007). Functional impairment of the retinoid cycle, resulting in insufficient regeneration of 11-cis-retinal and excess of unliganded, constitutively active opsin, often results in progressive retinopathies and eventual loss of vision (Woodruff et al., 2003; Fan et al., 2005; Travis et al., 2007). Limitations of current medical interventions for retinal degenerative diseases emphasize the need to establish therapies that are more effective. Pharmacologic supplementation with the iso-chromophore 9-cis-retinal that eliminates the

ABBREVIATIONS: ABCA4, ATP-binding cassette subfamily A, member 4; AF, autofluorescence; BTP, bis-tris propane; 11-cis-6mr-retinal, 11-cis6-membered ring-retinal; DAPI, 4'6'-diamidino-2-phenyl-indole; DDM, n-dodecyl- $\beta$-D-maltoside; DHE, dihydroethidium; DMSO, dimethylsulfoxide; ERG, electroretinography; LRAT, lecithin retinol acyltransferase; MS, mass spectrometry; ONL, outer nuclear layer; PNA, peanut agglutinin; RDH8, retinol dehydrogenase 8; ROS, reactive oxygen species; RPE, retinal pigment epithelium; SD-OCT, spectral domain-optical coherence tomography; SLO, scanning laser ophthalmoscopy; TPM, two-photon microscopy; WT, wild-type. 
constitutive activity of ligand-free opsin can dramatically improve visual function in mouse models of Leber congenital amaurosis (LCA) and Stargardt disease (Batten et al., 2004; Maeda et al., 2009b and c; Palczewski, 2010). Despite this positive finding, lengthy treatment with 9-cis-retinal can enhance the toxicity if pigment regeneration is delayed or clearance of photoproducts is defective (Woodruff et al., 2003; Fan et al., 2005). Thus, treatment with an 11-cis-6-membered ring-retinal (11-cis-6mr-retinal) chromophore analog could constitute a viable complementary or alternative approach. This retinal contains a ring between $\mathrm{C}^{10}$ and $\mathrm{C}^{13}$ instead of the double bond between $\mathrm{C}^{11}=\mathrm{C}^{12}$, which prevents its isomerization from the 11-cis to all-trans configuration and locks this retinal analog in the chromophore binding pocket (Bhattacharya et al., 1992). Thus, therapy with 11-cis-6mrretinal could bypass the excessive accumulation of all-transretinal in the retina released from the activated receptors under bright light conditions without abridging phototransduction because rod opsin bound to 11-cis-6mr-retinal exhibits residual sensitivity to light in vivo and in vitro (Fan et al., 2002; Kuksa et al., 2002; Gulati et al., 2017). Moreover, this retinal analog does not bind to cone opsin efficiently, eliminating the risk of fast deactivation of cone pigment signaling (Alexander et al., 2017).

We investigated the effect of 11-cis-6mr-retinal on acute light-induced retinal degeneration in $\mathrm{Abca4^{-1- }} \mathrm{Rdh}^{-{ }^{-1}}$ mice, a model that resembles many features of human Stargardt disease (Maeda et al., 2008, 2009c; Chen et al., 2012; Fujinami et al., 2015), in which exposure to bright light causes prominent photoreceptor cell death owing to buildup of all-trans-retinal released from photobleached rhodopsin with subsequent activation of oxidative stress (Chen et al., 2012).

\section{Materials and Methods}

Chemicals and Reagents. Dodecyl- $\beta$-D-maltopyranoside (DDM) (Affymetrix Inc., Maumee, $\mathrm{OH}$ ) was used to solubilize opsin from mouse retinas. 4'6'-Diamidino-2-phenyl-indole (DAPI) and Alexa594-conjugated goat anti-mouse secondary antibody were purchased from Life Technologies (Grand Island, NY) for nuclear staining and immunostaining, respectively. Dimethylsulfoxide DMSO and 9-cis-retinal were obtained from Sigma-Aldrich Corp. (St. Louis, MO). D5-all-trans-retinal was purchased from Toronto Research Chemicals (Toronto, ON). 11-cis-6mrretinal was synthesized as described previously and obtained from Novartis (Cambridge, MA) (Alexander et al., 2017; Gulati et al., 2017). Mouse monoclonal 1D4 anti-rhodopsin antibodies were purified from hybridoma cells also as described previously (Adamus et al., 1988, 1991; Hodges et al., 1988).

Animals: Care and Treatment. $A b c a 4^{-1-} R d h 8^{-1-}$ mice (Maeda et al., 2008) with a pigmented C57BL/6 or C57BL/6 and 129SV mixed background were used for light-induced retinal degeneration assays and

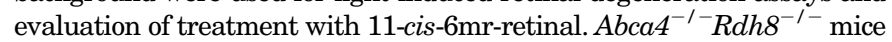
were genotyped to confirm that they lack of the $R d 8$ mutation. Only mice with the Leu variation at amino acid 450 of retinal pigment epithelium (RPE)65 were used (Kim et al., 2004). BALB/c mice (Jackson Laboratory, Bar Harbor, ME) at 4-6 weeks of age were also used to test the effects of 11-cis-6mr-retinal on bright light-induced retinal damage. C57BL/6 mice (Jackson Laboratory) were used to test the effect of 11-cis-6mr-retinal on the retinoid cycle and the accumulation of retinoids in the eye. Both male and female mice were used in all experiments. 11-cis-6mr-retinal was dissolved in DMSO and administered to mice by i.p. injection at 4$20 \mathrm{mg} / \mathrm{kg}$ b.wt. All mice were housed in the Animal Resource Center at the School of Medicine, Case Western Reserve University (CWRU) and maintained in a 12 -hour light ( $\leq 10,000$ lux)/dark cycle. Manipulations in the dark were performed under dim red light. All animal procedures and experimental protocols were approved by the Institutional Animal Care and Use Committee at CWRU and conformed to recommendations of both the American Veterinary Medical Association Panel on Euthanasia and the Association for Research in Vision and Ophthalmology.

Bright Light-Induced Retinal Degeneration. Retinal degeneration was initiated by exposing dark-adapted $\mathrm{Abca4^{-1- }} R \mathrm{dh} 8^{-/-}$or $\mathrm{BALB} / \mathrm{c}$ mice to 10,000 or 12,000 lux white light, respectively, delivered from a 150-W spiral lamp (Hampton Bay; Home Depot, Atlanta, GA) for 30 or 60 minutes, as previously described (Chen et al., 2013). Before light exposure, pupils of $A b c a 4^{-/-} R d h 8^{-1-}$ mice were dilated with $1 \%$ tropicamide, but this was not needed for BALB/c mice. 11-cis-6mr-Retinal or DMSO was administered intraperitoneally 30 minutes before exposure to bright light. Effects of 11-cis-6mrretinal were tested at $4,8,12$, and $20 \mathrm{mg} / \mathrm{kg}$ of body weight. Each injection volume was $70 \mu \mathrm{l}$. Retinal morphology and function were analyzed in vivo by spectral domain optical coherence tomography (SD-OCT) and electroretinography (ERG) 7 days after bright light exposure. Mice then were euthanized, and their eyes were subjected to staining with H\&E, immunohistochemistry, and imaging.

SD-OCT. To evaluate the effect of 11-cis-6mr-retinal treatment on $A b c a 4^{-1-} R d h 8^{-1-}$ mice or BALB/c mice after bright light-induced retinal damage, we performed in vivo imaging of mouse retinas with ultrahigh-resolution SD-OCT (Bioptigen, Morrisville, NC) (Chen et al., 2013). Briefly, pupils of mice were first dilated with $1 \%$ tropicamide. Then, mice were anesthetized by intraperitoneal injection of a cocktail containing ketamine $(20 \mathrm{mg} / \mathrm{ml})$ and xylazine $(1.75 \mathrm{mg} / \mathrm{ml})$ at a dose of $4 \mu \mathrm{l} / \mathrm{g}$ b.wt. The A scan/B scan ratio was set at 1200 lines. Four frames of OCT images scanned at 0 and 90 degrees were acquired in the B-mode, averaged, and saved as PDF files. To evaluate changes in the retinas of mice exposed to bright light and assess the effect of 11-cis-6mr-retinal on retinal protection, the outer nuclear layer (ONL) thickness was measured $500 \mu \mathrm{m}$ from the optic nerve head. Each treatment group contained 10 mice, and the experiment was repeated three times. Values of ONL thickness were plotted using means and standard deviation.

Scanning Laser Ophthalmoscopy Imaging. Scanning laser ophthalmology (SLO) (Heidelberg Engineering, Franklin, MA) was performed for in vivo whole-fundus imaging of mouse retinas (Huber et al., 2009). Mice were anesthetized, and their pupils were dilated with $1 \%$ tropicamide before imaging. SLO was acquired in the autofluorescence mode, and the number of autofluorescent spots was counted and subjected to statistical analysis.

Retinal Histology. The structural morphology of mouse retinas subjected to bright light and pretreated with either 11-cis-6mr-retinal or DMSO as a control were assessed in vitro using H\&E staining of paraffin sections. Mice were euthanized, and their eyes were removed and fixed in $4 \%$ paraformaldehyde and $1 \%$ glutaraldehyde, followed by paraffin sectioning. Sections ( $5 \mu \mathrm{m}$ thick) were stained with H\&E and imaged by light microscopy (Leica, Wetzlar, Germany).

Immunohistochemistry. Eyes collected from mice exposed to bright light were fixed in cryoembedding medium and processed for cryosectioning. Morphology of the retinas was assessed by immunostaining of $12-\mu \mathrm{m}$-thick cryosections with monoclonal 1D4 antirhodopsin primary antibody and Alexa Fluor 594-conjugated goat anti-mouse immunoglobulin $\mathrm{G}$ used as a secondary antibody to detect rod photoreceptors. To detect cone photoreceptors biotinylated peanut agglutinin (PNA) and Alexa Fluor 488-conjugated streptavidin were used. Nuclear staining was achieved with DAPI.

Two-Photon Microscope Imaging. Three days after lightinduced retinal degeneration, $\mathrm{Abca4^{-/- }} R d h 8^{-/-}$albino mice on a C57BL/6 and 129SV background treated either with DMSO or 11-cis$6 \mathrm{mr}$-retinal 30 minutes before light stimulation for 60 minutes were subjected to two-photon (TPM) imaging as described previously (Maeda et al., 2014). Briefly, a Leica TCS SP5 upright confocal microscope equipped with a 1.0-NA water immersion objective and tunable laser Vision S (Coherent) delivering 75-fs laser pulses at an $80-\mathrm{MHz}$ pulse repetition frequency was used to image freshly 
A

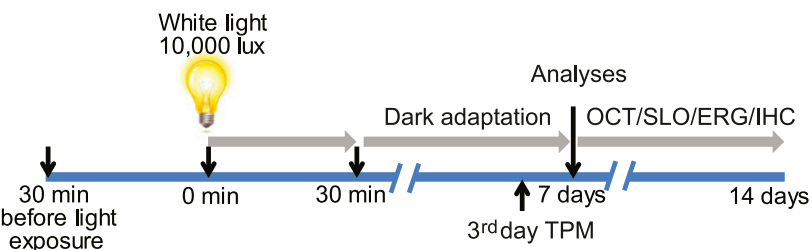

B
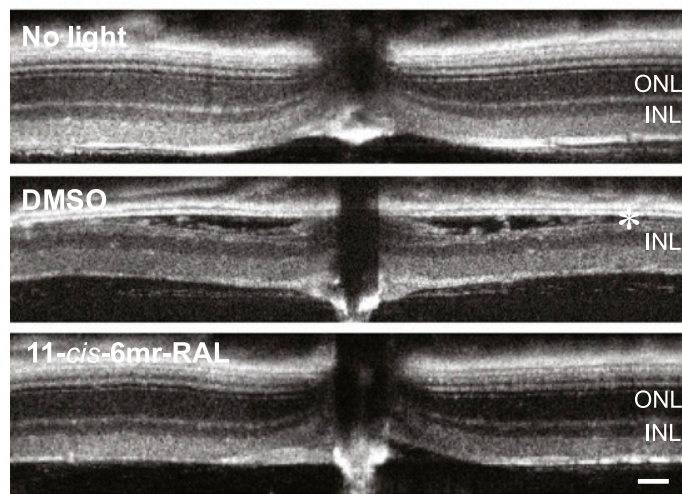

D
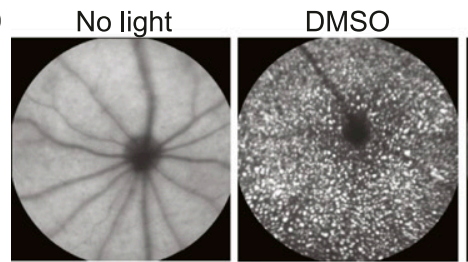

11-cis-6mr-RAL

F

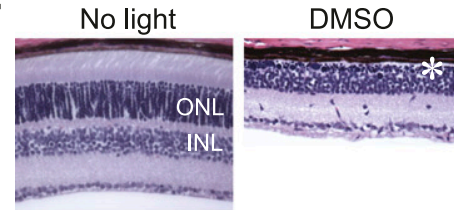

C

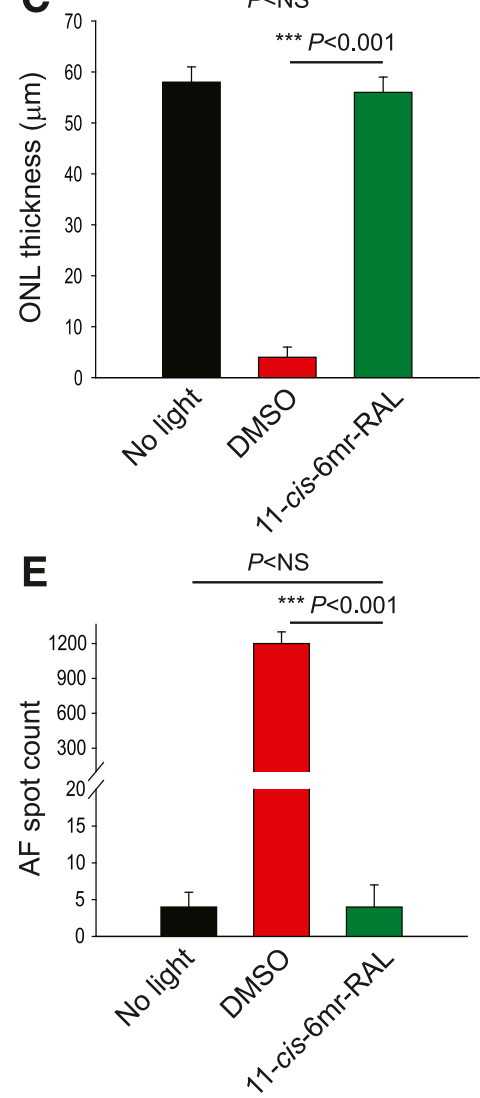

G
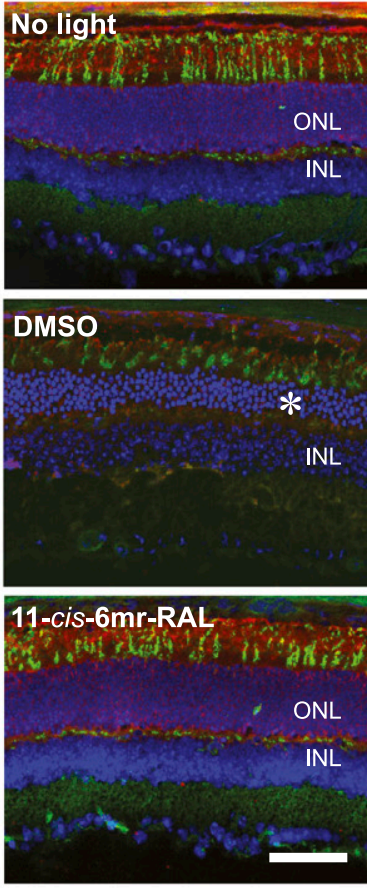

Rho/PNA/DAPI

Fig. 1. Protective effect of 11-cis-6mr-retinal against bright-light-induced retinal degeneration in $A b c a 4^{-1-} R d h 8^{-1-}$ mice. (A) Scheme of mouse treatment. 11-cis-6mr-retinal or DMSO vehicle was administered to 4-6-week-old $A b c a 4^{-1-} R d h 8^{-1-}$ or WT BALB/c mice by intraperitoneal injection 30 minutes before exposure to bright light (10,000 lux) for 30 minutes for $A b c a 4^{-1-} R d h 8^{-/-}$mice and 12,000 lux for 60 minutes for WT BALB/c mice. Then, mice were kept in the dark for 7-14 days before examination. The morphology of the retina was assessed by OCT and SLO in vivo imaging, as well as by H\&E staining and immunohistochemistry. Retinal function was assessed by ERG. TPM imaging was used to determine abnormalities in photoreceptor cells on the 4th day after treatment. (B) Representative OCT images obtained 7 days after treatment of mice with 11 -cis-6mr-retinal (20 mg/kg b.wt.) 30 minutes before exposure to white light at 10,000 lux for 30 minutes. After light illumination, mice were kept in the dark until morphologic examination. INL, inner nuclear layer. Asterisk indicates severely disrupted photoreceptor structures in DMSO-treated control mice. (C) Quantification of the ONL thickness obtained in 10 mice per treatment group. Error bars indicate standard deviations. Changes in the ONL thickness observed after treatment with 11-cis-6mr-retinal compared with DMSO-treated group were statistically significant $(P<0.001)$; no significant difference in the ONL thickness was observed between animals unexposed to light and those treated with 11-cis-6mr-retinal $(P=\mathrm{NS})$. Statistical significance was calculated with the one-way analysis of variance and post hoc Student's $t$ test, unpaired two-tailed. (D) Representative SLO images show AF spots in the retina of a mouse exposed to light after pretreatment with DMSO (center). Mice unexposed to bright light (left) or exposed to bright light after pretreatment with 11-cis-6mr-retinal (right) exhibited much fewer spots. (E) Quantification of AF spots performed in 10 mice per treatment group. Error bars indicate standard deviation. Changes in the number of AF spots after treatment with 11-cis-6mr-retinal compared with the DMSOtreated group were statistically significant $(P<0.001)$. No significant difference was observed between animals unexposed to light and those exposed to light after treatment with 11-cis-6mr-retinal $(P=\mathrm{NS})$. Statistical significance was calculated with one-way ANOVA and post hoc, the Student's $t$ test, unpaired two-tailed. (F) Examination of retinal morphology after staining with H\&E in paraffin sections prepared from eyes collected from $A b c a 4^{-1-} R d h 8^{-/-}$mice either unexposed to light or exposed to bright light after the indicated treatments. Asterisk indicates severely disrupted photoreceptor structures in DMSO-treated control mice. (G) Examination of retinal morphology by immunohistochemistry in cryosections prepared from the eyes collected from $A b c a 4^{-1-} R d h 8^{-1-}$ mice either unexposed to light or exposed to bright light after the indicated treatments. Sections were stained with an anti-rhodopsin C terminus specific antibody (red), which indicates the structural organization of rod photoreceptors; PNA staining (green), which indicates the health of cone photoreceptors; and DAPI staining of nuclei (blue). Asterisk indicates severely disrupted photoreceptor structures in DMSO-treated control mice. Scale bar, $50 \mu \mathrm{m}$.

enucleated intact mouse eyes. Before eye enucleation, mice were anesthetized by intraperitoneal injection of a cocktail containing ketamine $(6 \mathrm{mg} / \mathrm{ml})$ and xylazine $(0.44 \mathrm{mg} / \mathrm{ml})$ at a dose of $10 \mu \mathrm{g} / \mathrm{g} \mathrm{b}$. wt. and then euthanized.

Detection of Reactive Oxygen Species In Vivo. Detection and quantification of reactive oxygen species (ROS) generated in vivo in $A b c a 4^{-/-} R d h 8^{-/-}$mice after exposure to bright light was performed as described previously (Chen et al., 2013). Dihydroethidium (DHE), a ROS probe, was administered to mice by intraperitoneal injection at a dose of $20 \mathrm{mg} / \mathrm{kg}$ b.wt. delivered in $50 \mu \mathrm{l}$ of DMSO vehicle 1 day after illumination with 10,000 lux white light. Thirty minutes before light exposure, these mice were also treated with 11-cis-6mr-retinal or vehicle. One hour after DHE administration, eyes were collected and fixed in cryoembedding medium. Cryosections (12 $\mu \mathrm{m}$ thick) were used 
TABLE 1

Dose-dependent effect of 11-cis-6mr-retinal on retinal health in $A b c a 4^{-1-} R d h 8^{-1-}$ mice

The thickness of the ONL and the number of AF spots were evaluated in OCT or SLO images, respectively, obtained from $A b c a 4^{-1-} R d h 8^{-1-}$ mouse eyes under different treatments. Mice were kept in the dark, treated with DMSO, or with different doses $(4,8,12$, or $20 \mathrm{mg} / \mathrm{kg})$ of 11-cis-6mr-retinal 30 minutes before bright-light illumination. Morphologic changes induced by bright light were largely prevented by pretreatment with 11-cis-6mr-retinal at $20 \mathrm{mg} / \mathrm{kg}$; the ONL thickness and AF spot counts closely resembled those of mice not exposed to bright light. Partial protection was achieved with 11-cis-6mr-retinal at $12 \mathrm{mg} / \mathrm{kg}$. Statistical significance was calculated with the Student's $t$ test, unpaired two-tailed for two-group comparison, and one-way ANOVA test (SigmaPlot 11.0 software) for multiple group comparison.

\begin{tabular}{lcccc}
\hline \multicolumn{1}{c}{ Treatment } & $\begin{array}{c}\text { OCT ONL } \\
\text { Thickness }\end{array}$ & $\begin{array}{c}\text { Statistical } \\
\text { Significance }(P)\end{array}$ & $\begin{array}{c}\text { SLO AF, } \\
\text { Spot Counts }\end{array}$ & $\begin{array}{c}\text { Statistical } \\
\text { Significance }(P)\end{array}$ \\
\hline No light & $\mu m$ & P value & Spot counts & P value \\
DMSO & $58 \pm 3$ & NA & $4 \pm 2$ & NA \\
11-cis-6mr-retinal (4 mg/kg b.wt.) & $4 \pm 2$ & NA & $1200 \pm 100$ & NA \\
11-cis-6mr-retinal (8 mg/kg b.wt.) & $15 \pm 10$ & $<0.05$ & $1100 \pm 200$ & NS \\
11-cis-6mr-retinal (12 mg/kg b.wt.) & $27 \pm 18$ & $<0.001$ & $400 \pm 200$ & $<0.05$ \\
11-cis-6mr-retinal (20 mg/kg b.wt.) & $58 \pm 3$ & $<0.001$ & $4 \pm 3$ & $<0.001$ \\
\hline
\end{tabular}

$\mathrm{AF}$, autofluorescence; ANOVA, analysis of variance; DMSO, dimethylsulfoxide; NA, not applicable; NS, not statistically significant; OCT, optical coherence tomography; ONL, outer nuclear layer; SLO, scanning laser ophthalmoscopy.

for microscopic evaluation of ROS fluorescence in the retina. Quantification of ROS fluorescence was performed with ImageJ software (NIH).

Electroretinography Analyses. To evaluate the protective effect of 11-cis-6mr-retinal on retinal function, ERG recordings were obtained for $A b c a 4^{-/-} R d h 8^{-/-}$mice or BALB/c mice at 4 to 5 weeks of age 7-14 days after light-induced damage. These mice were divided into an unbleached group, a DMSO-treated control group and an 11-cis-6mr-retinal-treated group. Ten $A b c a 4^{-1-} R d h 8^{-1-}$ and five $\mathrm{BALB} / \mathrm{c}$ mice were used in each group. The mice were given a single dose of 11 -cis-6mr-retinal at $20 \mathrm{mg} / \mathrm{kg}$ by intraperitoneal injection 30 minutes before light exposure. Before ERG recording, darkadapted mice were anesthetized with $20 \mathrm{mg} / \mathrm{ml}$ ketamine and $1.75 \mathrm{mg} / \mathrm{ml}$ xylazine in phosphate-buffered saline at a dose of 0.1$0.13 \mathrm{ml} / 25 \mathrm{~g}$ b.wt., and pupils were dilated with $1 \%$ tropicamide. Contact lens electrodes were placed on the eyes, and a reference electrode was positioned between two ears, whereas a ground electrode was placed on the tail. Scotopic and photopic ERGs were recorded for both eyes of each mouse using a UTAS E-3000 universal testing and ERG system (LKC Technologies, Inc., Gaithersburg, MD). ERG data represent the means and standard deviations of both a-wave and b-wave amplitudes.

To evaluate the effect of 11-cis-6mr-retinal on the retinoid cycle, wild-type (WT) C57BL/6J mice were placed in a dark room 1 day before ERG measurements. DMSO, 11-cis-6mr-retinal at a dose of $20 \mathrm{mg} / \mathrm{kg}$ b.wt. or retinylamine (a potent inhibitor of the visual cycle) (Golczak et al., 2005b) at a dose of $4 \mathrm{mg} / \mathrm{kg}$ b.wt. were administrated by intraperitoneal injection 30 minutes before light exposure. Mice were treated with $1 \%$ tropicamide eye drops for pupil dilation, exposed to 2000 lux of illumination for 5 minutes, and returned to the dark. Mice were anesthetized after bleaching for scotopic ERG recordings as described previously (Maeda et al., 2005). Briefly, every 5 minutes, a single-flash scotopic ERG at a stimulating intensity of $1.6 \mathrm{~cd} \cdot \mathrm{s} \cdot \mathrm{m}^{-2}$ was recorded within 1 hour after light exposure. A-wave and b-wave amplitudes of each ERG recording were measured, averaged from five animals, and plotted as a function of time using Sigma Plot software version 11.

Purification of Retinal Pigment. Eyes were collected from three $\mathrm{Abca4^{-1- }} R d h 8^{-/-}$or WT C57BL/6J mice, which were either dark-adapted or treated with 11-cis-6mr-retinal at a dose of $20 \mathrm{mg} / \mathrm{kg}$ b.wt. 30 minutes before bright-light exposure for 30 minutes, followed by housing in the dark for 24 hours. This treatment was repeated three times. Additionally, eyes were collected from lecithin retinol aclyltransferase knockout $\left(\mathrm{Lrat}^{-{ }^{-}-}\right)$mice either untreated or treated with 11-cis-6mr-retinal at the same dose as $A b c a 4^{-1-} R d h 8^{-1-}$ or WT C57BL/6J mice. Eyes were stored at $-80^{\circ} \mathrm{C}$ or used immediately. Eyes were homogenized gently with a glass-glass homogenizer in buffer composed of $50 \mathrm{mM}$ bis-tris propane (BTP), $\mathrm{pH} 7.5,150 \mathrm{mM}$ $\mathrm{NaCl}, 1 \mathrm{mM}$ EDTA, and protease inhibitor cocktail in the dark, followed by a 15 -minute centrifugation at $16,000 \mathrm{~g}$ in a benchtop Eppendorff centrifuge at $4^{\circ} \mathrm{C}$. Supernatants were discarded, and pellets were solubilized in $20 \mathrm{mM}$ BTP, pH 7.5, $100 \mathrm{mM} \mathrm{NaCl}$, $20 \mathrm{mM}$ n-dodecyl- $\beta$-D-maltoside for 1 hour at $4^{\circ} \mathrm{C}$. Solubilized membrane lysates were cleared by centrifugation at $16,000 \mathrm{~g}$ for 30 minutes, and the supernatants were incubated with 1D4immunoaffinity resin ( $6 \mathrm{mg}$ of 1D4 anti-rhodopsin antibody/ml resin) equilibrated with $20 \mathrm{mM}$ BTP, pH 7.5, $100 \mathrm{mM} \mathrm{NaCl}, 2 \mathrm{mM}$ DDM for 1 hour at $4^{\circ} \mathrm{C}$. After washing, rhodopsin and 11-cis-6mr-retinal-bound opsin were eluted by the addition of 1D4 peptide (TETSQVAPA) to the preceding buffer and spectra were then measured with a UV-visible spectrophotometer.

Detection and Quantification of 11-cis-6mr-Retinal in the Mouse Eye. To measure the amount of 11-cis-6mr-retinal in mouse eye after its systemic delivery, 11-cis-6mr-retinal was administered to $A b c a 4^{-\prime-} R d h 8^{-\prime-}$ mice in DMSO vehicle by intraperitoneal injection at a dose of $20 \mathrm{mg} / \mathrm{kg}$ b.wt. Then mice were kept in the dark for 24 hours and either euthanized to collect their eyes for analysis or the treatment was repeated twice.

Eyes from one mouse under the same treatment were homogenized on ice in $1 \mathrm{ml}$ of phosphate-buffered saline:methanol $(1: 1, \mathrm{v} / \mathrm{v})$ in the presence of $100 \mathrm{pmol}$ of an internal standard (d5-all-trans-retinal). The homogenate was incubated with $50 \mathrm{mM}$ hydroxylamine for 20 minutes at room temperature. Then, $4 \mathrm{ml}$ of hexane was added to the homogenized sample, and the mixture was vortexed for 15 seconds. The mixture was centrifuged at $3220 \mathrm{~g}$ for 5 minutes at $4^{\circ} \mathrm{C}$ to separate the hexanes from the aqueous layer. From the top hexane layer, $3.5 \mathrm{ml}$ was transferred to a glass vial. These samples were then dried in a Savant speedvac concentrator (Thermofisher, Waltham, MA) and dissolved in $300 \mu \mathrm{l}$ of hexane. Ten microliters of dissolved samples were injected into an Agilent Technology Santa Clara, CA) 1100 highperformance liquid chromatography system, and retinoids were separated on an xBridge C18 column $(3.5 \mu \mathrm{m}, 2.1 \times 100 \mathrm{~mm}$; Waters, Milford, MA) by a linear gradient of acetonitrile in water (50\%-100\%, 30 minutes, at at flow rate of $0.5 \mathrm{ml} / \mathrm{min}$ ). All solvents contained $0.1 \%$ formic acid (v/v). MS-based detection and quantification of 11-cis-6mrretinal were performed with an LTQ linear ion trap mass spectrometer (Thermo Scientific) equipped with an electrospray ionization interface operated in the positive ionization mode. Parameters of ionization and detection were tuned with synthetic oximes of the locked retinal. 11-cis-6mr-Retinal oximes and d5-all-trans-retinal oximes were detected in the selected reaction monitoring mode using $\mathrm{m} / \mathrm{z} 312.3 \rightarrow 295.2$ and $305.3 \rightarrow 247.2$ transitions, respectively. Calibration curves were calculated based on the linear relationship between areas under selected reaction monitoring ion intensity peaks 

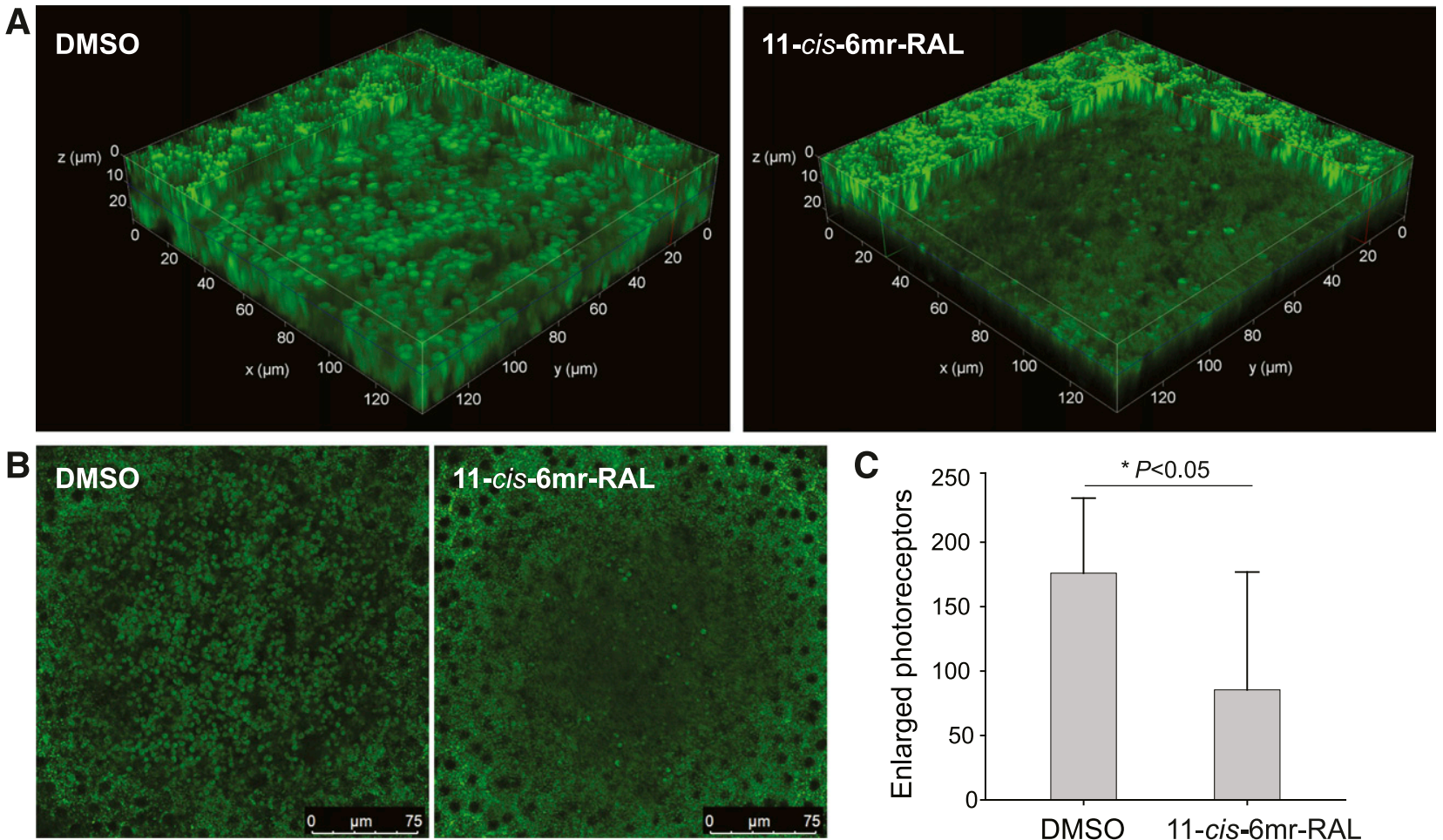

Fig. 2. Treatment with 11-cis-6mr-retinal protects photoreceptor cells from light-induced degeneration. $A b c a 4^{-1-} R d h 8^{-/-}$albino mice on a C57B6/J and 129SV background were treated with 11-cis-6mr-retinal $(20 \mathrm{mg} / \mathrm{kg}$ b.wt.) or DMSO vehicle 30 minutes before bright-light exposure for $60 \mathrm{minutes}$ and then kept in the dark. On day 3 after light exposure, TPM imaging was performed in intact mouse eyes immediately after enucleation to quantify enlarged photoreceptors and assess the effect of 11-cis-6mr-retinal. (A) Three-dimensional views of the photoreceptor-RPE interface. Enlarged photoreceptors are visible as fluorescent pillars with a diameter $>2 \mu \mathrm{m}$ (the diameter of unaffected photoreceptors was $\sim 1.2 \mu \mathrm{m}$ ). The center of the RPE layer was set at $z=0 \mu \mathrm{m}$, and the section through the photoreceptor cell layer is shown $10 \mu \mathrm{m}$ below. (B) Representative, large-field images of the retina and RPE are shown. The RPE is visible at the edges of the images as the curvature of the intact eyeball brings it in focus. (C) Quantification of the enlarged photoreceptors. The number of enlarged photoreceptors caused by illumination with bright light was significantly decreased $(P=0.02)$ in mice treated with 11-cis-6mr-retinal before light exposure. Error bars represent S.D. Statistical significance was calculated with the Student's $t$ test, unpaired two-tailed.

corresponding to the locked retinal oximes and the internal standard versus molar ratios of the compounds in a range of $20-500 \mathrm{pmol}$. The experiment was done in triplicate.

Statistical Analyses. Values of ONL thickness derived from SD-OCT imaging, counts of enlarged photoreceptors from TPM imaging, and counts of autofluorescent (AF) spots from SLO imaging are expressed as means \pm standard deviation. Five or 10 mice per treatment group were used. For two-group comparisons, Student's $t$ test was used. For multiple comparisons, the one-way analysis of variance (using SigmaPlot 11.0 software) with the post hoc Student's $t$ test was used. Differences were considered statistically significant at a $P$ value of $<0.05\left(* P<0.05, * * P<0.01,{ }^{* * *} P<0.001\right)$.

\section{Results}

11-cis-6mr-Retinal Protects against Bright LightInduced Retinal Degeneration in $\mathrm{Abca4}^{-1-} \mathrm{Rdh}^{-1-}$ Mice. $A b c a 4^{-1-} R d h 8^{-l-}$ mice lack both the ATP-binding cassette transporter 4 (ABCA4) and the all-trans-retinol dehydrogenase 8 (RDH8) enzyme and exhibit impaired clearance of all-trans-retinal photoproducts (Molday, 2007). They also feature many phenotypic changes found in patients with human juvenile macular degeneration (Maeda et al., 2008, 2014). These mice develop both chronic retinal degeneration under ambient light resembling the human condition, as well as intense light-induced acute retinal degeneration. Thus, they serve as a model of both rod and cone photoreceptor degeneration. In this study, we evaluated the protective effect of the locked chromophore analog, 11-cis-6mr-retinal, against bright light-induced retinal degeneration. To determine the therapeutic dose of 11-cis-6mr-retinal, various concentrations of this retinal analog $(4,8,12$, or $20 \mathrm{mg} / \mathrm{kg}$ body weight or a DMSO vehicle were administered to 4-6-week-old $A b c a 4^{-1-} R d h 8^{-1-}$ mice by intraperitoneal injection 30 minutes before exposure to 10,000 lux bright light for 30 minutes. These mice then were kept in the dark for 7-14 days to allow clearing of dead cells before their evaluation as schematically depicted in Fig. 1A. Analysis of retinal morphology by in vivo OCT imaging revealed that morphologic damage induced by bright light was largely prevented by pretreatment with 11-cis-6mr-retinal at $20 \mathrm{mg} / \mathrm{kg}$ and retinal structures closely resembled those of mice not exposed to bright light (Fig. 1, B and C; Table 1). Partial protection was noted with 11-cis-6mr-retinal at $12 \mathrm{mg} / \mathrm{kg}$ (Table 1). In contrast, control mice treated with DMSO vehicle exhibited disruption of photoreceptors manifested by severe changes in the thickness of the ONL (Fig. 1, B and C).

Increased $\mathrm{AF}$ in the photoreceptor outer segments and $\mathrm{RPE}$ associated with brigh-light illumination was previously observed (Maeda et al., 2008, 2011a). Thus, we quantified AF spots in the eyes of $A b c a 4^{-1-} R d h 8^{-1-}$ mice pretreated with 11-cis-6mr-retinal or DMSO vehicle, followed by bright-light exposure and compared these values with untreated and unilluminated mice. SLO imaging was performed to detect 

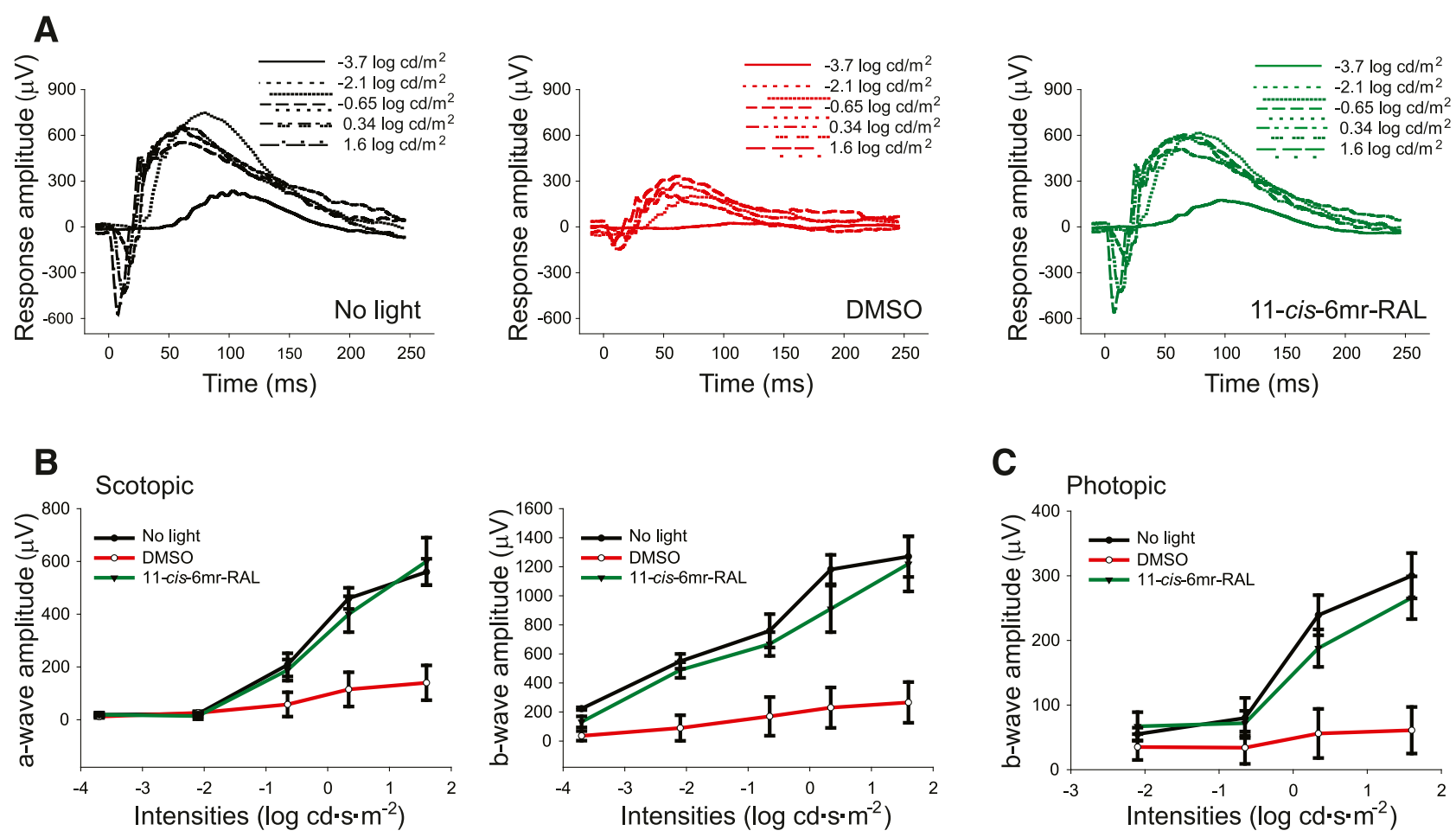

Fig. 3. Effect of 11-cis-6mr-retinal pretreatment on visual function in $A b c a 4^{-1-} R d h 8^{-1-}$ mice exposed to bright light. (A) Single-flash ERG responses to increasing light intensity obtained under dark conditions in mice either unexposed to light or exposed to bright light after treatment with either DMSO or 11-cis-6mr-retinal at a dose of $20 \mathrm{mg} / \mathrm{kg}$ b.wt. (B) ERG responses compared between treatment groups revealed significant protective effects in 11-cis-6mrretinal-treated mice before acute light illumination as compared with DMSO-treated mice in both scotopic a- and b-waves and in photopic b-waves (C). ERG measurements were carried out in 10 mice per group.

AF 7 days after treatment (Fig. 1A). The number of AF spots was greatly increased in DMSO-treated mice, whereas it was decidedly decreased in mice pretreated with 11-cis-6mrretinal at $20 \mathrm{mg} / \mathrm{kg} 30$ minutes before exposure to bright light (Fig. 1, D and E). A partial decrease in AF spots was noted with 11-cis-6mr-retinal at $12 \mathrm{mg} / \mathrm{kg}$ (Table 1). Thus, the results obtained from retinal SLO imaging correlated with the retinal degeneration detected with OCT imaging.

To confirm the results obtained from in vivo analyses, we performed histologic examination of plastic sections after $\mathrm{H} \& \mathrm{E}$ staining from areas like those used for OCT imaging (Fig. 1F). The diminished ONL in DMSO-treated $\mathrm{Abca4^{-1- }} R d h \mathrm{8}^{-1-}$ mice exposed to bright light, as well as the protective effect of treatment with 11-cis-6mr-retinal, agreed with the findings from OCT imaging.

Treatment with 11-cis-6mr-Retinal Preserves Retinal Morphology after Exposure to Bright Light in $\boldsymbol{A b c a 4}^{-/-} \boldsymbol{R d h}^{-1-}$ Mice. To assess light-induced damage to the retina in greater detail, we performed an immunohistochemical analysis of cryosections stained with an anti-rhodopsin antibody that labeled rod outer segments and PNA that labeled cone cells. DAPI staining was used to detect nuclei. As shown in Fig. 1G, Abca $4^{-1-} R d h 8^{-1-}$ mice treated with DMSO vehicle showed severe changes in retinal morphology evidenced by a significantly decreased thickness of the ONL. Also, PNA staining was undetectable, and only residual staining of rhodopsin remained; however, pretreatment with 11-cis-6mr-retinal before bright-light exposure prevented light-induced damage and preserved the morphology of photoreceptors. Images of retinal morphology of 11-cis-6mr-retinal-treated mice closely resembled those images from mice unexposed to light, as demonstrated by a similar thickness of the ONL and intense staining with antirhodopsin antibodies and PNA.

Treatment with 11-cis-6mr-Retinal Reduces Photoreceptor Death. One of the early manifestations of light-induced retinal degeneration is the swelling of the photoreceptor cells (Maeda et al., 2014). We performed TPM imaging to assess and quantify changes in photoreceptor morphology in freshly enucleated mouse eyes 3 days after treatment with 11-cis$6 \mathrm{mr}$-retinal and exposure to bright light. DMSO-treated $A b c a 4^{-1-} R d h 8^{-1-}$ control mice showed a marked increase of enlarged photoreceptors, whereas pretreatment with 11-cis$6 \mathrm{mr}$-retinal before light illumination significantly diminished the number of such photoreceptors (Fig. 2).

Treatment with 11-cis-6mr-Retinal Preserves Retinal Function. ERG analysis of the visual response was used to assess retinal function. The results were compared between three groups of mice: $A b c a 4^{-1} R d h 8^{-/-}$mice unexposed to light, DMSO-treated and exposed to bright light, or 11-cis-6mr-retinaltreated and exposed to bright light. Both scotopic a- and b-waves and photopic b-waves were nearly eradicated in $A b c a 4^{-1-} R d h 8^{-1-}$ mice treated with DMSO vehicle, followed by 10,000 lux bright-light illumination (Fig. 3, A and B). Importantly, pretreatment with 11-cis-6mr-retinal before light exposure almost completely preserved visual acuity in these mice. Both scotopic aand b-waves and photopic b-waves of 11-cis-6mr-retinal-treated mice were quite similar to those of mice unexposed to bright light.

11-cis-6mr-Retinal Prevents Light-Induced Retinal Damage and Preserves Retinal Function in WT Mice. To determine whether 11-cis-6mr-retinal protects against 
A
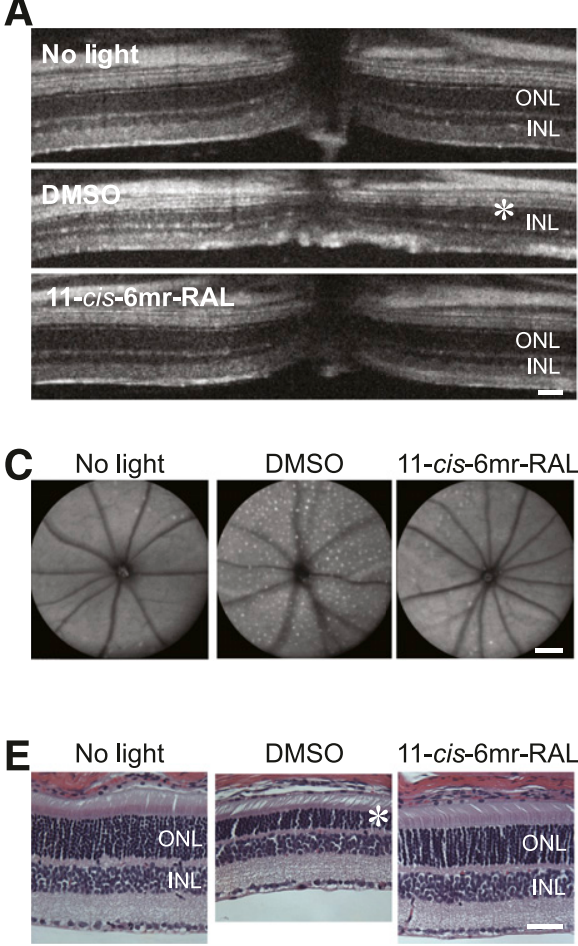

DMSO

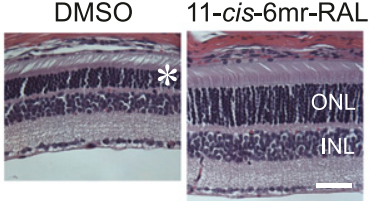

B

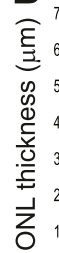

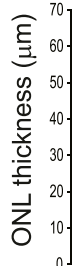
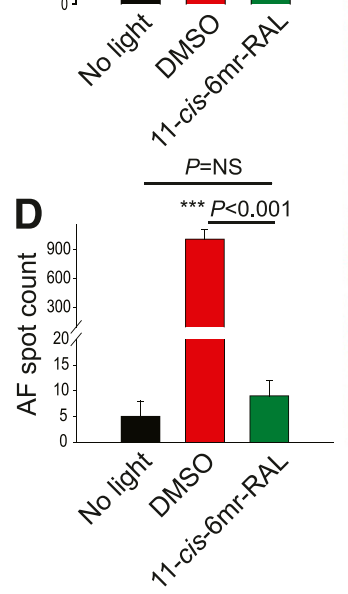

$\mathbf{F}$
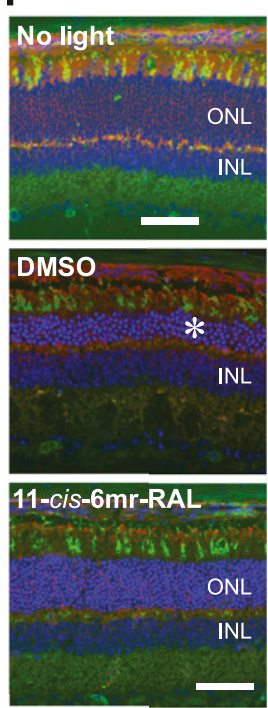

Rho/PNA/DAPI
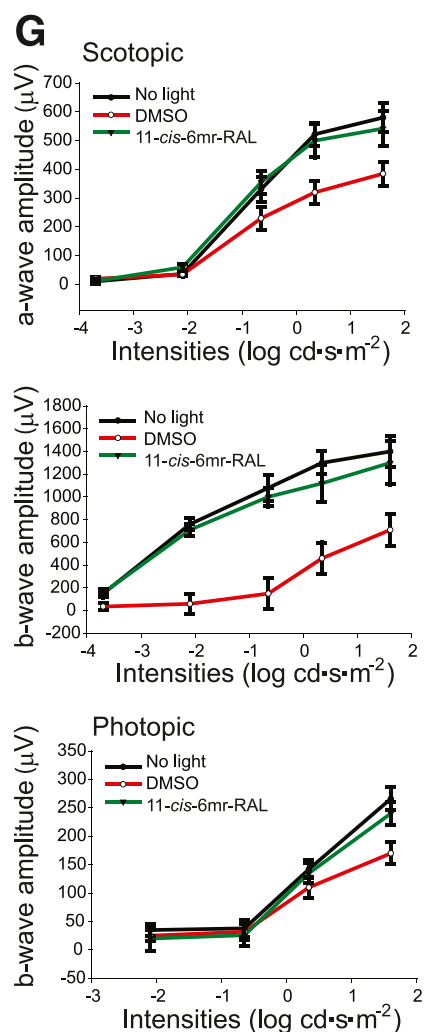

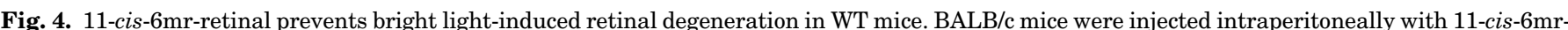

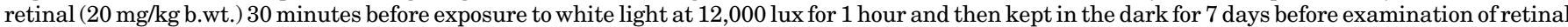

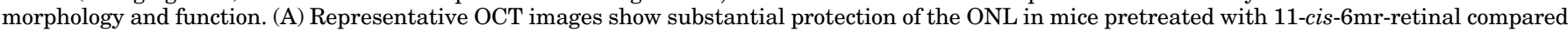

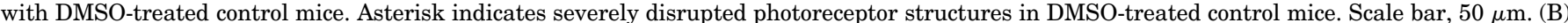

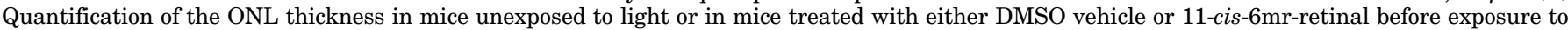

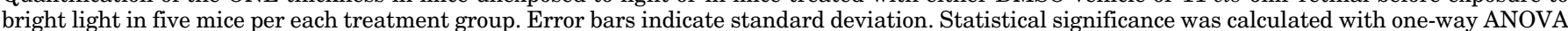

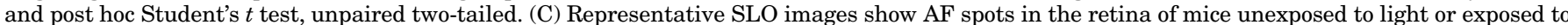

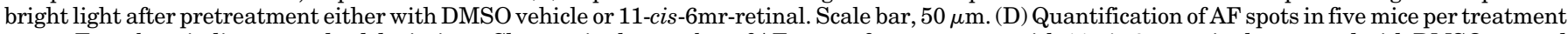

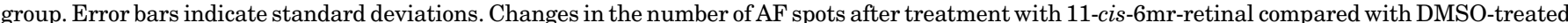

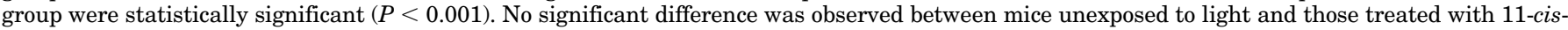

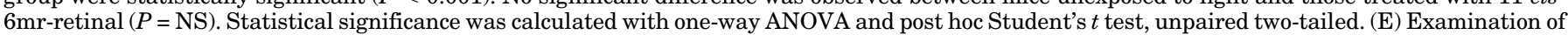

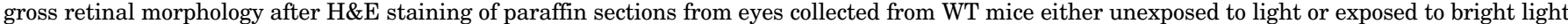

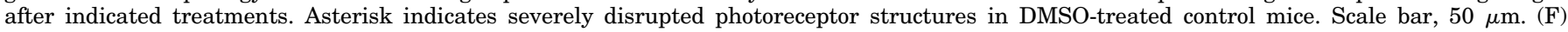

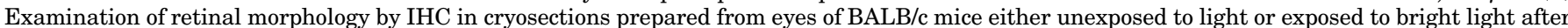

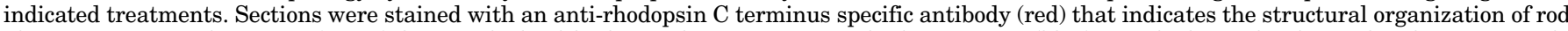

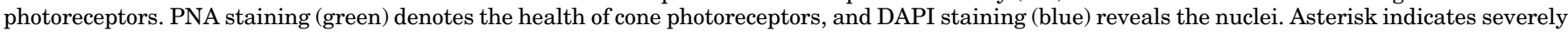

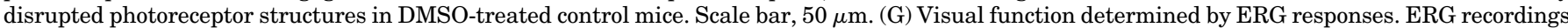

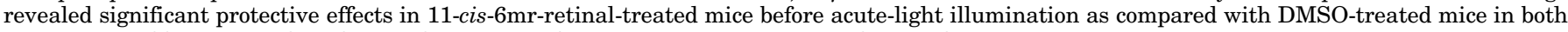
scotopic a- and b-waves and in photopic b-waves. ERG measurements were carried out in five mice per group.

light-induced retinopathy in WT mice, we used 6-8-week-old albino BALB/c mice susceptible to light-induced retinal degeneration (LaVail et al., 1987a,b). As evidenced by OCT images, pretreatment with 11-cis-6mr-retinal 30 minutes before bright-light exposure prevented noticeable retinal damage in DMSO-treated control mice (Fig. 4, A and B). Seven days after bright-light illumination, DMSO-treated WT mice featured severe disorganization of retinal structures and thinning of the ONL, just like $A b c a 4^{-/-} R d h 8^{-/-}$mice. In agreement with OCT images, SLO imaging revealed a significant reduction in the number of $\mathrm{AF}$ spots associated with light-induced retinal pathology in animals treated with 11-cis6mr-retinal (Fig. 4, C and D). Histologic examination of retinas from WT mice further confirmed the protective effect of 11-cis-6mr-retinal (Fig. 4E). Immunohistochemical analysis of cryosections stained with an anti-rhodopsin antibody to label rods and PNA to label cones also confirmed morphologic changes in the retina, as evidenced by a decreased thickness of the ONL in mice treated with DMSO before light exposure. Notably, pretreatment with 11-cis-6mr-retinal significantly preserved photoreceptor morphology. The ONL was much thicker than in DMSO-treated mice and closely resembled the ONL thickness in mice unexposed to light (Fig. 4F). As revealed by ERG responses, consistent with the morphologic changes observed in these mice, visual function that diminished after exposure to bright light was almost completely preserved after pretreatment with 11-cis-6mr-retinal (Fig. 4G).

Treatment with 11-cis-6mr-Retinal Does Not Inhibit the Retinoid Cycle. To determine whether 11-cis-6mrretinal affects the retinoid cycle, we measured the ERG response recovery in WT C57BL/6J mice within 1 hour after illumination with white light at 2000 lux for 5 minutes. Before illumination, these mice were treated with DMSO vehicle, 11-cis-6mr-retinal, or retinylamine; the last agent is a potent inhibitor of the visual cycle (Golczak et al., 2005). Immediately 


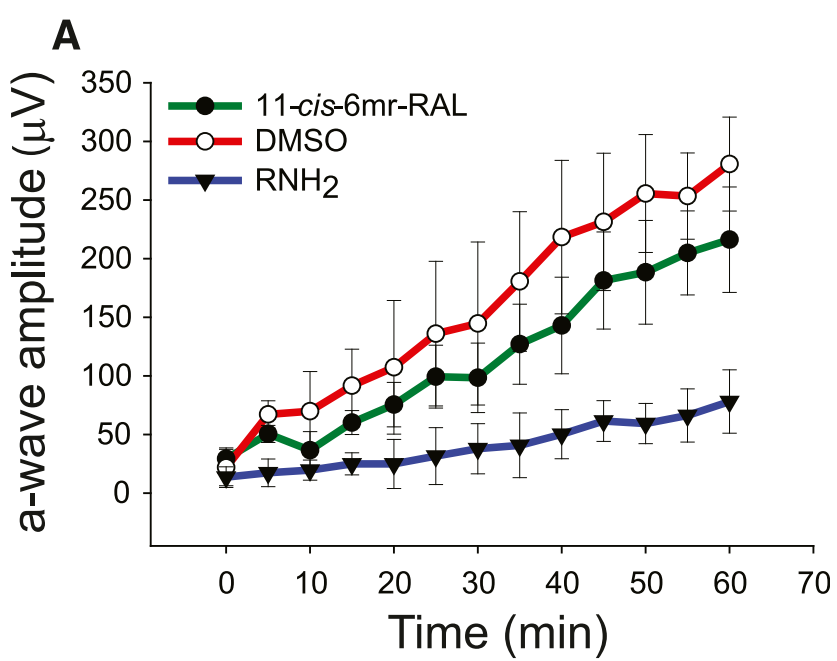

B

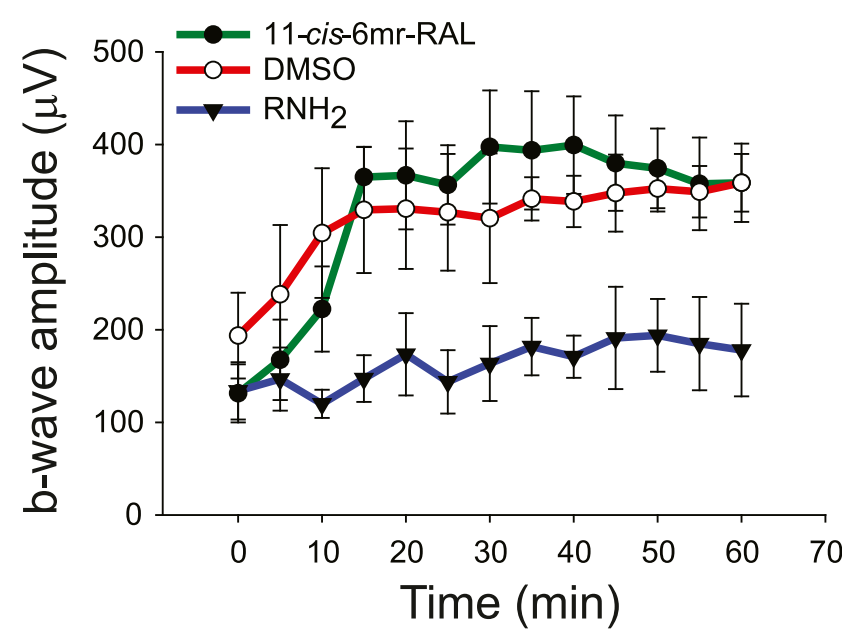

Fig. 5. Effect of 11-cis-6mr-retinal on the retinoid cycle. WT C57BL/6J mice were injected intraperitoneally with DMSO vehicle, 11-cis-6mrretinal at a dose of $20 \mathrm{mg} / \mathrm{kg}$ b.wt., or retinylamine [a potent inhibitor of the visual cycle (Golczak et al., 2005)] at a dose of $4 \mathrm{mg} / \mathrm{kg}$ b.wt., 30 minutes before illumination with white light at 2000 lux for 5 minutes. Scotopic ERG responses were recorded immediately after exposure to light and every 5 minutes thereafter for a total of 60 minutes. Increasing amplitudes of both a-waves (A) and b-waves (B) after light illumination in mice treated either with DMSO or 11-cis-6mr-retinal were noted but were much slower in mice treated with retinylamine. Five mice per group were used for these ERG measurements. Error bars represent standard deviation.

after exposure to light, scotopic ERG responses were recorded every 5 minutes for a total of 1 hour. As shown in Fig. 5, recovery of both a-wave (Fig. 5A) and b-wave (Fig. 5B) amplitudes after illumination in mice treated either with DMSO or 11-cis-6mr-retinal was evident, but not in mice treated with retinylamine. Thus, 11-cis-6mr-retinal did not inhibit the conversion of all-trans-retinal to its 11-cis configuration.

Treatment with 11-cis-6mr-Retinal Inhibits ROS Generation in $\mathrm{Abca4}^{-/} \mathrm{Rdh}^{-/-}$Mice after BrightLight Exposure. Oxidative stress that causes overproduction of ROS is considered the major mechanism of photoreceptor cell death induced by acute light exposure in model animals (Organisciak et al., 1992; Donovan et al., 2001). Excessive production of ROS in $A b c a 4^{-1-} R d h 8^{-1-}$ mice from bright light illumination has been documented (Chen et al., 2013).
Maintaining low levels of ROS, therefore, is extremely important for the viability of photoreceptor cells. Here, we tested whether treatment with 11-cis-6mr-retinal could reduce the generation of ROS in $A b c a 4^{-1-} R d h 8^{-/-}$mice exposed to bright light. Dark-adapted mice were injected with the fluorescent probe DHE, used to detect superoxide radicals, 1 day after exposure to 10,000-lux light for 30 minutes. ROS signals detected in the ONL were then compared between three groups of mice: those unexposed to light, DMSO-treated controls, and mice pretreated with 11-cis-6mr-retinal. The highest production of ROS was detected in vehicle-treated mice, whereas the ROS signal in the ONL was substantially decreased in mice treated with 11-cis-6mr-retinal to a level similar to that observed in dark-adapted mice (Fig. 6). Together, these data indicate that ROS generation contributing to light-induced retinopathy in $A b c a 4^{-1-} R d h 8^{-1-}$ mice is mitigated by treatment with 11-cis-6mr-retinal, thereby protecting photoreceptor cells.

Accumulation of 11-cis-6mr-Retinal in the Eye. The constitutive activity of ligand-free opsin accelerates the degeneration of photoreceptors (Woodruff et al., 2003; Fan et al., 2005). Coupling of a locked retinal analog, 11-cis-6mr-retinal, to unliganded opsin would not only mitigate unwanted opsin activity, but it also would prevent its release from the binding pocket upon illumination and thus could contribute to the protective mechanism against light-induced retinal pathology. The 11-cis-6mr-retinal analog binds to rod opsin, resulting in formation of a pigment with a different absorption maximum (Gulati et al., 2017). This property was used to determine whether the formation of 11-cis-6mr-retinal-bound pigment could be detected in the mix of rhodopsin and 11-cis$6 \mathrm{mr}$-retinal-bound opsin after their purification from mouse eyes. $A b c a 4^{-1-} R d h 8^{-1-}$ and WT mice were used. A difference in absorption maxima between samples purified from nontreated mice and mice treated with 11-cis-6mr-retinal was difficult to detect in normal dark spectra, likely owing to the high amount of rhodopsin overlapping with 11-cis-6mrretinal-bound opsin; however, a small shift in the absorption peak toward longer wavelengths with a maximum at $\sim 505 \mathrm{~nm}$ was noted in the difference spectra, when spectra obtained after illumination were subtracted from the dark spectra (Fig. 7, $\mathrm{A}$ and $\mathrm{B}$ ). Thus, these results indicate that 11-cis-6mrretinal-bound opsin was formed in vivo in the eyes of mice treated with 11-cis-6mr-retinal before illumination. As an additional control for binding of 11-cis-6mr-retinal to rod opsin, we used $\mathrm{Lrat}^{-1-}$ mice in which regeneration of rhodopsin is impaired and opsin accumulates in rod outer segments (Batten et al., 2004). After being kept in the dark, these mice were injected with a single dose of 11-cis-6mrretinal for three consecutive days. UV-visible spectra of the protein purified from the eyes of these mice revealed that opsin regeneration with 11-cis-6mr-retinal had occurred and the pigment had an absorption peak maximum at $508 \mathrm{~nm}$ (Fig. 7C), further supporting the hypothesis that silencing the constitutive activity of opsin could serve as a protective mechanism against light-induced retinal damage in mouse eyes.

To further confirm and to quantify the accumulation of 11-cis-6mr-retinal in the mouse eye, liquid chromatographymass spectrometry (MS)-based analyses were performed. Retinoids were extracted from eyes of $A b c a 4^{-1-} R d h 8^{-1-}$ mice treated with either a single intraperitoneal injection or 

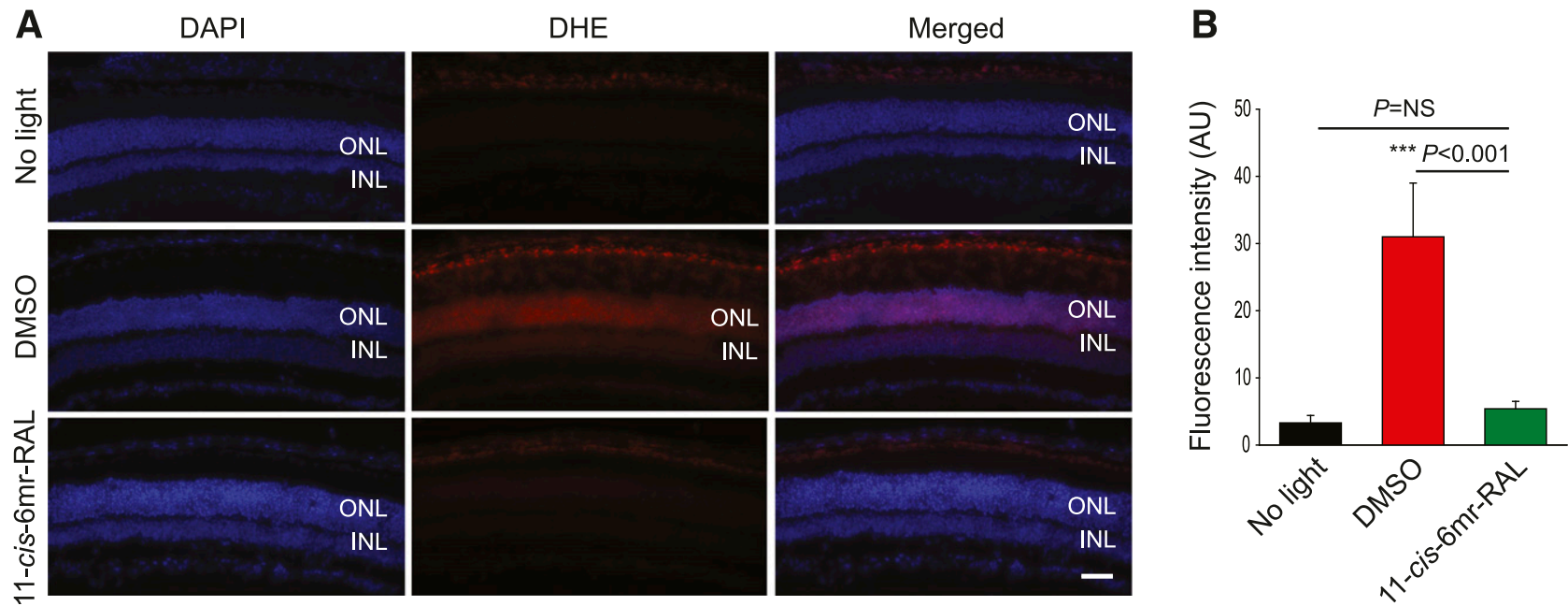

Fig. 6. Effect of 11-cis-6mr-retinal on photoreceptor generation of ROS in $A b c a 4^{-1-} R d h 8^{-/-}$mice exposed to bright light. (A) Dark-adapted Abca $4^{-1-} R d h 8^{-/-}$mice were injected intraperitoneally with the ROS probe DHE 1 day after illumination with 10,000 lux white light for 30 minutes. These mice were treated with either DMSO or 11-cis-6mr-retinal $(20 \mathrm{mg} / \mathrm{kg}$ b.wt.) 30 minutes before light exposure. Mice unexposed to bright light also were treated with the DHE probe. Eyes were harvested 1 hour later, fixed, and processed for cryosectioning. The ROS signal detected on sections from different experimental groups, was obtained with a fluorescence microscope. DAPI staining was used to visualize nuclei and the retinal layers. Scale bar, $50 \mu \mathrm{m}$. (B) Quantification of fluorescence intensity in arbitrary units obtained from various regions of the photoreceptor cell layers (mean \pm standard deviation). Changes in fluorescence intensity observed in the photoreceptor layers after treatment with 11-cis-6mr-retinal compared with the DMSOtreated group were statistically significant $(P<0.001)$. No significant difference was observed between mice unexposed to light and those treated with 11-cis-6mr-retinal $(P=\mathrm{NS})$. Statistical significance was calculated with the one-way ANOVA and post hoc Student's $t$ test, unpaired two-tailed.

three consecutive injections of 11-cis-6mr-retinal. An internal standard (d5-all-trans-retinal) was added to the eye homogenate before retinoid extraction to enable MS-based quantification of 11-cis-6mr-retinal retained in the eye. The results obtained from liquid chromatography-MS analyses confirmed accumulation of 11-cis-6mr-retinal in the eyes of $A b c a 4^{-1-} R d h 8^{-1-}$ mice (Fig. 8, A-C). Quantification revealed the presence of the locked retinal analog in the eyes of these mice after a single administration with a concentration in the low picomolar range ( $\sim 6 \mathrm{pmol})$ and its additive accumulation after three injections ( 12 pmol) (Fig. 8C). Twenty-four hours postadministration, most drugs would likely be eliminated unless they remained bound to a targeted molecule. Thus, detection of 11-cis-6mr-retinal 1 day after its administration and additive accumulation 4 days later after multiple administrations indicate that the retinoid analog penetrates and persists in the eye by stably binding to opsin.

\section{Discussion}

Excessive light can be detrimental to retinal health (Organisciak et al., 1998; Maeda et al., 2008; Chen et al., 2012). Overstimulation of rhodopsin with bright light triggers photoreceptor cell damage and ultimately blindness (Grimm et al., 2000; Rózanowska and Sarna, 2005; German et al., 2015). Interestingly, rhodopsin knockout mice are completely protected from such light-induced retinal damage, suggesting that rhodopsin is required for phototoxicity to occur (Grimm et al., 2000; Hao et al., 2002; Jacobson and McInnes 2002). The elevated concentrations of all-trans-retinal and its byproducts, which accumulate in photoreceptors after stimulation by bright light, are a leading cause of retinopathy. These materials are especially harmful when they overaccumulate and pigment regeneration is defective (Chen et al., 2012). Stargardt disease, an inherited juvenile form of age-related macular degeneration, typifies these situations (Weng et al.,
1999). Patients with Stargardt disease experience progressive rod-cone dystrophy associated with an overaccumulation of lipofuscin and drusen, thickening of Bruch's membrane, and choroidal neovascularization (Maeda et al., 2008, 2012, 2014). A mutation in the ABCA4 transporter found in these patients interferes with the transport of released all-trans-retinal from the inner space of the rod outer-segment discs to the cytoplasm, resulting in buildup of this retinoid and its metabolite, the bis-retinoid N-retinylidene-N-retinylethanolamine (Molday, 2007; Wu et al., 2009; Conley et al., 2012). Further, the insufficient conversion of all-trans-retinal back to its 11-cis form in such a condition also results in delayed regeneration of visual pigment. In fact, loss of rod and cone sensitivity appears in these patients before anatomic changes to the retina are detectable (Jackson et al., 2014; Salvatore et al., 2014).

Decreasing levels of all-trans-retinal either with inhibitors of the retinoid cycle such as retinylamine (Golczak et al., 2005) and the retinylamine-derived potent inhibitor emixustat (Kubota et al., 2014; Zhang et al., 2015) or Food and Drug Administration-approved drugs containing amines that sequester accumulated free aldehyde (Maeda et al., 2011) can significantly improve overall retinal health in $\mathrm{Abca4^{-1- }} R d h 8^{-1-}$ mice, corroborating that all-trans-retinal is the toxic photometabolite.

High levels of rhodopsin $(\sim 5 \mathrm{mM})$ are expressed in rod photoreceptor cells (Palczewski, 2006). Thus, in patients with Stargardt disease, illumination of only $10 \%$ of the visual pigment would result in the prolonged exposure of toxic concentrations of free all-trans-retinal of $\sim 500 \mu \mathrm{M}$. Reversible conjugation of this highly cytotoxic retinoid with amino group-containing compounds has a protective effect against retinal damage (Maeda et al., 2011); however, high doses of such compounds are necessary to achieve a therapeutic outcome.

Inhibition of the visual cycle with specific inhibitors of enzymes involved in the regeneration of 11-cis-retinal decreases accumulation of all-trans-retinal and its by-products 

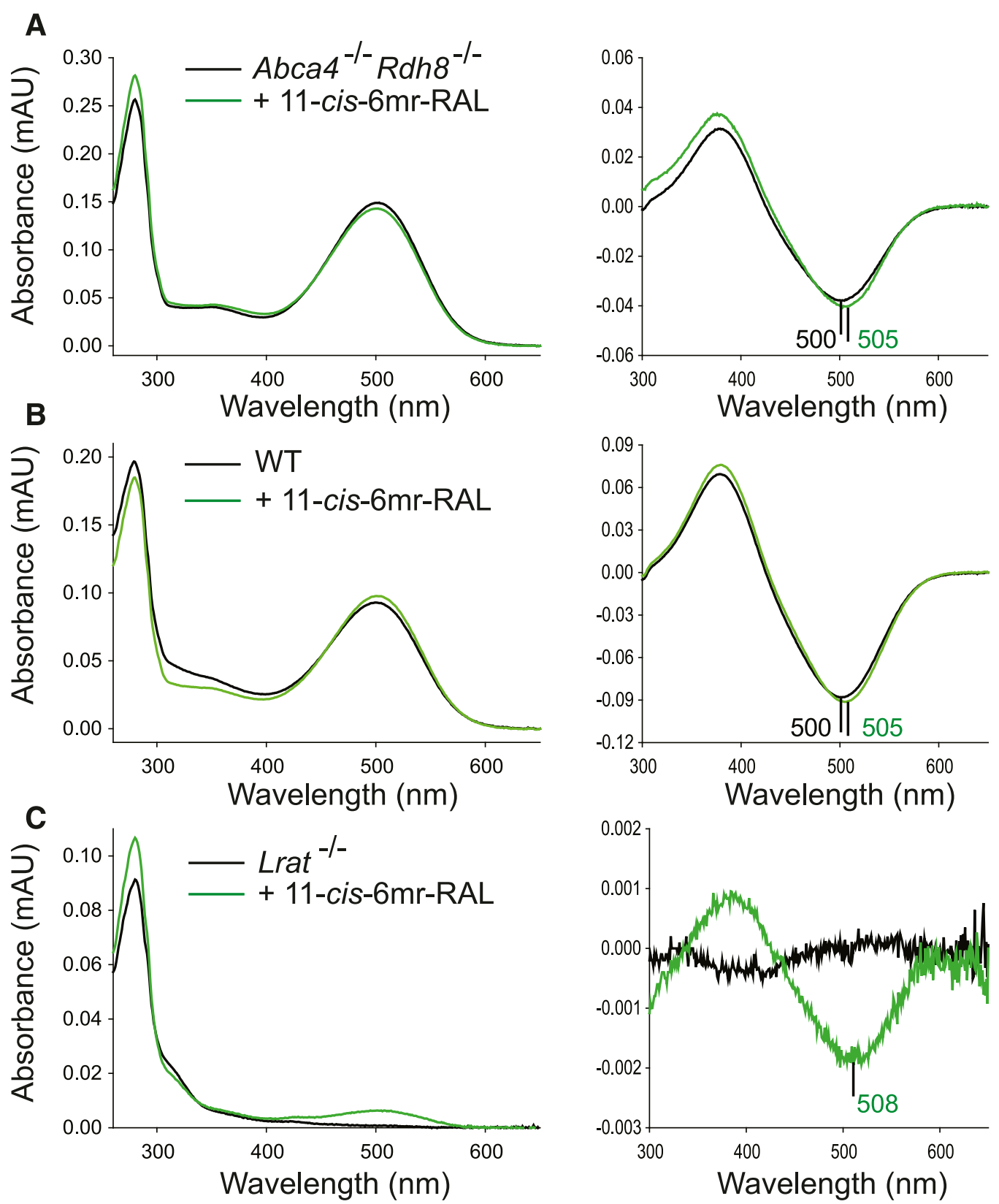

Fig. 7. Detection of 11-cis-6mr-retinal-bound pigment in mouse eyes. 11-cis-6mr-retinal $\left(20 \mathrm{mg} / \mathrm{kg}\right.$ b.wt.) was administered to $A b c a 4^{-/-} R d h 8^{-/-}$or WT mice 30 minute before their exposure to bright light for 30 minutes. After illumination, mice were kept in the dark. This procedure was repeated three times. On the 4th day ( 24 hours after the third treatment), eyes were harvested, and pigment was purified by 1D4 anti-rhodopsin immunoaffinity chromatography. Additionally, $\mathrm{Lrat}^{-1-}$ mice were injected intraperitoneally with 11-cis-6mr-retinal for three consecutive days, and 24 hours after the last injection, eyes were collected and used for pigment purification. UV-visible spectra of the rhodopsin or rhodopsin/11-cis-6mr-retinal-bound opsin

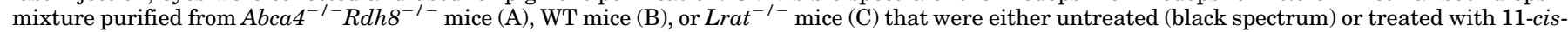
$6 \mathrm{mr}$-retinal (green spectrum), left panel. Difference spectra were obtained by subtracting the UV-visible spectrum of the light-illuminated sample from the spectrum recorded in the dark; right panel.

by slowing the regeneration of rhodopsin; however, prolonged inhibition of pigment regeneration could lead to an increase of chromophore-free opsin in photoreceptor cells that also accelerates retinal degeneration (Woodruff et al., 2003; Fan et al., 2005). In fact, administration of 9-cis-retinal acetate to Abca $4^{-1-} R d h 8^{-/-}$mice before stimulation with bright light limited retinal damage in these mice, indicating that in fact delayed regeneration of 11-cis-retinal can result in the accumulation of ligand-free opsin; however, pharmacologic supplementation with 9-cis-retinal does not address accumulation of all-trans-retinal and its by-products after light illumination when its regeneration to 11-cis-retinal and clearance from photoreceptors is faulty (Maeda et al., 2009; Palczewski, 2010). Therefore, we aimed to evaluate the effect of a locked chromophore analog, 11-cis-6mr-retinal, against bright light-induced retinal degeneration. The hypothesis was that 11-cis-6mr-retinal administered to $A b c a 4^{-1-} R d h 8^{-1-}$ mice before exposure to light would bind to opsin, silencing not only its toxic constitutive activity but also avoid excessive accumulation of all-trans-retinal owing to its locked conformation in the 

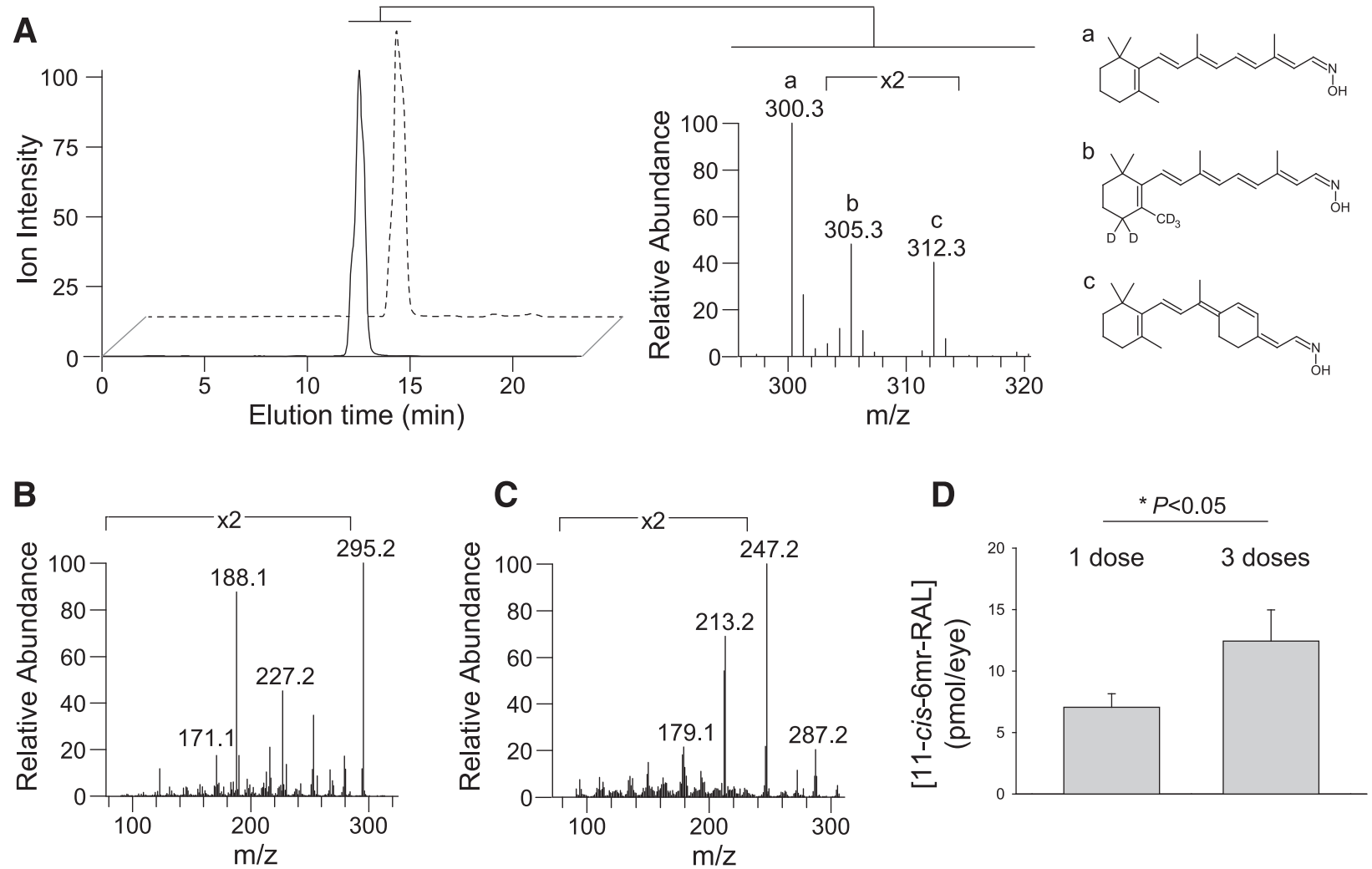

Fig. 8. Detection and quantification of 11-cis-6mr-retinal $(20 \mathrm{mg} / \mathrm{kg}$ b.wt.) in mouse eyes. (A) Elution profiles for 11-cis-6mr-retinal oximes (solid line) and d5-all-trans-retinal oximes (dashed line). Chromatograms represent ion intensities for $m / z=312.3[\mathrm{M}+\mathrm{H}]^{+}$and $\mathrm{m} / \mathrm{z}=305.3[\mathrm{M}+\mathrm{H}]^{+}$, respectively. The MS spectrum averaged between 12 and 13 minutes of elution indicates ions corresponding to the oximes of endogenous retinal $(\mathrm{a})\left(\mathrm{m} / \mathrm{z}=300.3[\mathrm{M}+\mathrm{H}]^{+}\right)$, d5-all-trans-retinal (b), and 11-cis-6mr-retinal (c). Fragmentation patterns for 11-cis-6mr-retinal oximes and d5-all-trans-retinal oximes are shown in (B) and $(\mathrm{C})$, respectively. Characteristic fragmentation profiles for these compounds were used to design the selected reaction monitoring-based detection and quantification method. (D), Dose-dependent accumulation of 11-cis-6mr-retinal retinal in mouse eyes of $A b c a 4^{-1-} R d h 8^{-1-}$. The observed accumulation of 11-cis-6mr-retinal in mouse eyes was statistically significant $(P<0.05)$. Statistical significance was calculated with the Student's $t$ test, unpaired two-tailed.

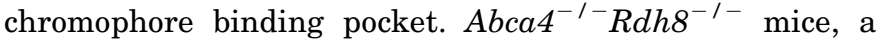
model of bright light-induced rod and cone photoreceptor degeneration, were used to test this hypothesis. The results also were confirmed in BALB/c WT mice, which are susceptible to retinal damage with strong light (LaVail et al., 1987a,b). Both $A b c a 4^{-1-} R d h 8^{-1-}$ and BALB/c WT mice developed severe retinal degeneration within 7 days after exposure to 10,000 or 12,000 lux light, respectively; however, retinopathy did not appear when mice were treated with 11-cis-6mr-retinal 30 minutes before light stimulation. As demonstrated by multiple imaging techniques, retinal structure, and specifically the morphology of rod and cone photoreceptors of mice pretreated with 11-cis-6mr-retinal, were comparable to that of mice kept in the dark, suggesting that avoiding the accumulation of unliganded opsin is critical to prevent or delay retinal degeneration in mice susceptible to light-induced damage. In fact, 11-cis-6mr-retinal was detected in the eyes of $A b c a 4^{-1-} R d h 8^{-/-}$mice 24 hours after administration, and its additive accrual was found after multiple consecutive doses as quantified by liquid chromatography-MS, indicating its stable binding to opsin. Although partial protection against light damage was observed earlier upon administration of 9-cis-retinal-acetate (Maeda et al., 2009), almost full protection was achieved with 11-cis-6mr-retinal treatment in this study. Moreover, pretreatment with 11-cis-6mr-retinal before bright-light insult not only prevented morphologic damage of the retina, but it also preserved visual acuity in treated mice. Furthermore, 11-cis-6mr-retinal did not impair the visual, retinoid cycle. As observed, the conversion of all-trans-retinal to 11-cisretinal was not inhibited in mice administered with 11-cis$6 \mathrm{mr}-$ retinal. This is not a surprising result because, as shown before, 11-cis-locked-retinals are poor substrates for the visual cycle enzymes, including 11-cis-retinal dehydrogenase (11-cis-RDH) and lecithin retinol acyltransferase (LRAT) (Kuksa et al., 2002).

Excessive concentrations of all-trans-retinal that induce oxidative stress through activation of the phospholipase $\mathrm{C} \rightarrow$ inositol-3-phosphate $\rightarrow \mathrm{Ca}^{2+}$ pathway and NADPH oxidase, resulting in photoreceptor death can be prevented with antioxidants (Chen et al., 2012, 2013, 2016). Such oxidative stress could also be reduced by cis-retinoids administered systematically at low levels in a mouse model of diabetic retinopathy (Berkowitz et al., 2015). Significantly, production of ROS in the photoreceptors of $A b c a 4^{-1-} R d h 8^{-I^{-}}$mice was completely inhibited by pretreatment with 11-cis-6mr-retinal, indicating its antioxidant properties at concentrations used in this study. Moreover, as evaluated by ERG recordings, photoreceptor function in vivo was fully preserved by 11-cis$6 \mathrm{mr}$-retinal given to mice before light stimulation. This result demonstrated that 11-cis-6mr-retinal has few, if any, adverse effects on phototransduction in this rodent model; however 
long-term follow-up studies would need to be performed to determine the toxicity profile for this compound.

In summary, this study demonstrates that 11-cis-6mr-retinal is a promising drug candidate against the development of lightinduced retinopathy in $A b c a 4^{-1-} R d h 8^{-1-}$ and WT mice. $A b c a 4^{-/-} R d h 8^{-/-}$rodents are used as a model of human Stargardt disease, associated with delayed clearance of alltrans-retinal photoproducts and delayed pigment regeneration. Therefore, results presented here add to our understanding of the mechanisms underlying a debilitating blinding condition and may offer therapeutic opportunities in the future, either alone or in combination with other treatments.

\section{Acknowledgments}

We thank Elizabeth Gutierrez for reading the manuscript and Dr. Muneto Mogi (Novartis Inc.) for the 11-cis-6mr-retinal.

\section{Authorship Contributions}

Participated in research design: Gao, Palczewski, Jastrzebska.

Conducted experiments: Gao, Parmar, Palczewska, Dong, Golczak, Jastrzebska.

Contributed new reagents or analytic tools: Golczak.

Performed data analysis: Gao, Parmar, Palczewska, Golczak, Jastrzebska.

Wrote or contributed to the writing of the manuscript: Gao, Golczak, Palczewski, Jastrzebska.

\section{References}

Adamus G, Arendt A, Zam ZS, McDowell JH, and Hargrave PA (1988) Use of peptides to select for anti-rhodopsin antibodies with desired amino acid sequence specificities. Pept Res 1:42-47.

Adamus G, Zam ZS, Arendt A, Palczewski K, McDowell JH, and Hargrave PA (1991) Anti-rhodopsin monoclonal antibodies of defined specificity: characterization and application. Vision Res 31:17-31.

Alexander NS, Katayama K, Sun W, Salom D, Gulati S, Zhang J, Mogi M, Palczewski $\mathrm{K}$, and Jastrzebska B (2017) Complex binding pathways determine the regeneration of mammalian green cone opsin with a locked retinal analogue. J Biol Chem 292:10983-10997.

Batten ML, Imanishi Y, Maeda T, Tu DC, Moise AR, Bronson D, Possin D, Van Gelder RN, Baehr W, and Palczewski K (2004) Lecithin-retinol acyltransferase is essential for accumulation of all-trans-retinyl esters in the eye and in the liver. $J$ Biol Chem 279:10422-10432.

Berkowitz BA, Kern TS, Bissig D, Patel P, Bhatia A, Kefalov VJ, and Roberts R (2015) Systemic retinaldehyde treatment corrects retinal oxidative stress, rod dysfunction, and impaired visual performance in diabetic mice. Invest Ophthalmol Vis Sci 56:6294-6303.

Bhattacharya S, Ridge KD, Knox BE, and Khorana HG (1992) Light-stable rhodopsin. I. A rhodopsin analog reconstituted with a nonisomerizable 11-cis retinal derivative. J Biol Chem 267:6763-6769.

Chen Y, Okano K, Maeda T, Chauhan V, Golczak M, Maeda A, and Palczewski K (2012) Mechanism of all-trans-retinal toxicity with implications for stargardt disease and age-related macular degeneration. J Biol Chem 287:5059-5069.

Chen Y, Palczewska G, Masuho I, Gao S, Jin H, Dong Z, Gieser L, Brooks MJ, Kiser PD, Kern TS, et al. (2016) Synergistically acting agonists and antagonists of G proteincoupled receptors prevent photoreceptor cell degeneration. Sci Signal 9:ra74.

Chen Y, Palczewska G, Mustafi D, Golczak M, Dong Z, Sawada O, Maeda T, Maeda A, and Palczewski K (2013) Systems pharmacology identifies drug targets for Stargardt disease-associated retinal degeneration. J Clin Invest 123:5119-5134.

Conley SM, Cai X, Makkia R, Wu Y, Sparrow JR, and Naash MI (2012) Increased cone sensitivity to ABCA4 deficiency provides insight into macular vision loss in Stargardt's dystrophy. Biochim Biophys Acta 1822:1169-1179.

Donovan M, Carmody RJ, and Cotter TG (2001) Light-induced photoreceptor apoptosis in vivo requires neuronal nitric-oxide synthase and guanylate cyclase activity and is caspase-3-independent. $J$ Biol Chem 276:23000-23008.

Fan G, Siebert F, Sheves M, and Vogel R (2002) Rhodopsin with 11-cis-locked chromophore is capable of forming an active state photoproduct. J Biol Chem 277: $40229-40234$.

Fan J, Woodruff ML, Cilluffo MC, Crouch RK, and Fain GL (2005) Opsin activation of transduction in the rods of dark-reared Rpe65 knockout mice. J Physiol 568:83-95.

Fujinami K, Zernant J, Chana RK, Wright GA, Tsunoda K, Ozawa Y, Tsubota K, Robson AG, Holder GE, Allikmets R, et al. (2015) Clinical and molecular characteristics of childhood-onset Stargardt disease. Ophthalmology 122:326-334.

German OL, Agnolazza DL, Politi LE, and Rotstein NP (2015) Light, lipids and photoreceptor survival: live or let die? Photochem Photobiol Sci 14:1737-1753.

Golczak M, Imanishi Y, Kuksa V, Maeda T, Kubota R, and Palczewski K (2005a) Lecithin:retinol acyltransferase is responsible for amidation of retinylamine, a potent inhibitor of the retinoid cycle. J Biol Chem 280:42263-42273.

Golczak M, Kuksa V, Maeda T, Moise AR, and Palczewski K (2005b) Positively charged retinoids are potent and selective inhibitors of the trans-cis isomerization in the retinoid (visual) cycle. Proc Natl Acad Sci USA 102:8162-8167.
Grimm C, Wenzel A, Hafezi F, Yu S, Redmond TM, and Remé CE (2000) Protection of Rpe65-deficient mice identifies rhodopsin as a mediator of light-induced retinal degeneration. Nat Genet 25:63-66.

Gulati S, Jastrzebska B, Banerjee S, Placeres AL, Miszta P, Gao S, Gunderson K, Tochtrop GP, Filipek S, Katayama K, et al. (2017) Photocyclic behavior of rhodopsin induced by an atypical isomerization mechanism. Proc Natl Acad Sci USA 114:E2608-E2615.

Hao W, Wenzel A, Obin MS, Chen CK, Brill E, Krasnoperova NV, Eversole-Cire P, Kleyner Y, Taylor A, Simon MI, et al. (2002) Evidence for two apoptotic pathways in light-induced retinal degeneration. Nat Genet 32:254-260.

Hodges RS, Heaton RJ, Parker JM, Molday L, and Molday RS (1988) Antigenantibody interaction. Synthetic peptides define linear antigenic determinants recognized by monoclonal antibodies directed to the cytoplasmic carboxyl terminus of rhodopsin. J Biol Chem 263:11768-11775.

Huber G, Beck SC, Grimm C, Sahaboglu-Tekgoz A, Paquet-Durand F, Wenzel A Humphries P, Redmond TM, Seeliger MW, and Fischer MD (2009) Spectral domain optical coherence tomography in mouse models of retinal degeneration. Invest Ophthalmol Vis Sci 50:5888-5895.

Jackson GR, Scott IU, Kim IK, Quillen DA, Iannaccone A, and Edwards JG (2014) Diagnostic sensitivity and specificity of dark adaptometry for detection of agerelated macular degeneration. Invest Ophthalmol Vis Sci 55:1427-1431.

Jacobson SG and McInnes RR (2002) Blinded by the light. Nat Genet 32:215-216.

Jastrzebska B (2013) GPCR: G protein complexes-the fundamental signaling assembly. Amino Acids 45:1303-1314.

Kim SR, Fishkin N, Kong J, Nakanishi K, Allikmets R, and Sparrow JR (2004) Rpe65 Leu450Met variant is associated with reduced levels of the retinal pigment epithelium lipofuscin fluorophores A2E and iso-A2E. Proc Natl Acad Sci USA 101:11668-11672.

Kiser PD, Golczak M, Maeda A, and Palczewski K (2012) Key enzymes of the retinoid (visual) cycle in vertebrate retina. Biochim Biophys Acta 1821:137-151.

Kiser PD, Golczak M, and Palczewski K (2014) Chemistry of the retinoid (visual) cycle. Chem Rev 114:194-232.

Kubota R, Al-Fayoumi S, Mallikaarjun S, Patil S, Bavik C, and Chandler JW (2014) Phase 1, dose-ranging study of emixustat hydrochloride (ACU-4429), a novel visual cycle modulator, in healthy volunteers. Retina 34:603-609.

Kuksa V, Bartl F, Maeda T, Jang GF, Ritter E, Heck M, Preston Van Hooser J, Liang Y, Filipek S, Gelb MH, et al. (2002) Biochemical and physiological properties of rhodopsin regenerated with 11-cis-6-ring- and 7-ring-retinals. J Biol Chem 277:42315-42324

LaVail MM, Gorrin GM, and Repaci MA (1987a) Strain differences in sensitivity to light-induced photoreceptor degeneration in albino mice. Curr Eye Res 6:825-834

LaVail MM, Gorrin GM, Repaci MA, and Yasumura D (1987b) Light-induced retinal degeneration in albino mice and rats: strain and species differences. Prog Clin Biol Res 247:439-454.

Maeda A, Golczak M, Chen Y, Okano K, Kohno H, Shiose S, Ishikawa K, Harte W, Palczewska G, Maeda T, et al. (2011a) Primary amines protect against retinal degeneration in mouse models of retinopathies. Nat Chem Biol 8:170-178.

Maeda A, Maeda T, Golczak M, Chou S, Desai A, Hoppel CL, Matsuyama S, and Palczewski K (2009a) Involvement of all-trans-retinal in acute light-induced retinopathy of mice. $J$ Biol Chem 284:15173-15183.

Maeda A, Maeda T, Golczak M, and Palczewski K (2008) Retinopathy in mice induced by disrupted all-trans-retinal clearance. J Biol Chem 283:26684-26693.

Maeda A, Maeda T, Imanishi Y, Kuksa V, Alekseev A, Bronson JD, Zhang H, Zhu L, Sun W, Saperstein DA, et al. (2005) Role of photoreceptor-specific retinol dehydrogenase in the retinoid cycle in vivo. J Biol Chem 280:18822-18832.

Maeda A, Palczewska G, Golczak M, Kohno H, Dong Z, Maeda T, and Palczewski K (2014) Two-photon microscopy reveals early rod photoreceptor cell damage in lightexposed mutant mice. Proc Natl Acad Sci USA 111:E1428-E1437.

Maeda T, Maeda A, Casadesus G, Palczewski K, and Margaron P (2009b) Evaluation of 9-cis-retinyl acetate therapy in Rpe65-/- mice. Invest Ophthalmol Vis Sci 50: $4368-4378$

Maeda T, Maeda A, Matosky M, Okano K, Roos S, Tang J, and Palczewski K (2009c) Evaluation of potential therapies for a mouse model of human age-related macular degeneration caused by delayed all-trans-retinal clearance. Invest Ophthalmol Vis Sci 50:4917-4925.

Maeda T, Perusek L, Amengual J, Babino D, Palczewski K, and von Lintig J (2011b) Dietary 9 -cis- $\beta, \beta$-carotene fails to rescue vision in mouse models of leber congenital amaurosis. Mol Pharmacol 80:943-952.

Molday RS (2007) ATP-binding cassette transporter ABCA4: molecular properties and role in vision and macular degeneration. J Bioenerg Biomembr 39:507-517.

Organisciak DT, Darrow RM, Barsalou L, Darrow RA, Kutty RK, Kutty G, and Wiggert B (1998) Light history and age-related changes in retinal light damage. Invest Ophthalmol Vis Sci 39:1107-1116.

Organisciak DT, Darrow RM, Jiang YI, Marak GE, and Blanks JC (1992) Protection by dimethylthiourea against retinal light damage in rats. Invest Ophthalmol Vis Sci 33:1599-1609.

Palczewski K (2006) G protein-coupled receptor rhodopsin. Annu Rev Biochem 75: 743-767.

Palczewski K (2010) Retinoids for treatment of retinal diseases. Trends Pharmacol Sci 31:284-295.

Park PS, Lodowski DT, and Palczewski K (2008) Activation of G protein-coupled receptors: beyond two-state models and tertiary conformational changes. Annu Rev Pharmacol Toxicol 48:107-141.

Rando RR (1996) Polyenes and vision. Chem Biol 3:255-262.

Rózanowska M and Sarna T (2005) Light-induced damage to the retina: role of rhodopsin chromophore revisited. Photochem Photobiol 81:1305-1330.

Salvatore S, Fishman GA, McAnany JJ, and Genead MA (2014) Association of darkadapted visual function with retinal structural changes in patients with Stargardt disease. Retina 34:989-995.

Travis GH, Golczak M, Moise AR, and Palczewski K (2007) Diseases caused by defects in the visual cycle: retinoids as potential therapeutic agents. Annu Rev Pharmacol Toxicol 47:469-512. 
von Lintig J (2012) Provitamin A metabolism and functions in mammalian biology. Am J Clin Nutr 96:1234S-1244S.

Weng J, Mata NL, Azarian SM, Tzekov RT, Birch DG, and Travis GH (1999) Insights into the function of Rim protein in photoreceptors and etiology of Stargardt's disease from the phenotype in abcr knockout mice. Cell 98: $13-23$

Woodruff ML, Wang Z, Chung HY, Redmond TM, Fain GL, and Lem J (2003) Spontaneous activity of opsin apoprotein is a cause of Leber congenital amaurosis. Nat Genet 35:158-164.

Wu Y, Fishkin NE, Pande A, Pande J, and Sparrow JR (2009) Novel lipofuscin bisretinoids prominent in human retina and in a model of recessive Stargardt disease. J Biol Chem 284:20155-20166.
Zhang J, Kiser PD, Badiee M, Palczewska G, Dong Z, Golczak M, Tochtrop GP, and Palczewski K (2015) Molecular pharmacodynamics of emixustat in protection against retinal degeneration. J Clin Invest 125:2781-2794.

Address correspondence to: Dr. Beata Jastrzebska, Department of Pharmacology, School of Medicine, Case Western Reserve University, 2109 Adelbert Rd, W343B, 10900 Euclid Ave., Cleveland, OH 44106-4965. E-mail: bxj27@case.edu; or Dr. Krzysztof Palczewski, Department of Pharmacology, School of Medicine, Case Western Reserve University, 10900 Euclid Ave., Cleveland, OH 44106-4965. E-mail: kxp65@case.edu 